\title{
Maria Kiseleva
}

\section{Oscillations of Dynamical Systems Applied in Drilling}

Analytical and Numerical Methods 


\title{
Maria Kiseleva
}

\section{Oscillations of Dynamical Systems Applied in Drilling}

\author{
Analytical and Numerical Methods
}

Esitetään Jyväskylän yliopiston informaatioteknologian tiedekunnan suostumuksella julkisesti tarkastettavaksi yliopiston Agora-rakennuksen Delta-salissa joulukuun 16. päivänä 2013 kello 12.

Academic dissertation to be publicly discussed, by permission of the Faculty of Information Technology of the University of Jyväskylä, in building Agora, auditorium Delta, on December 16, 2013 at 12 o'clock noon.

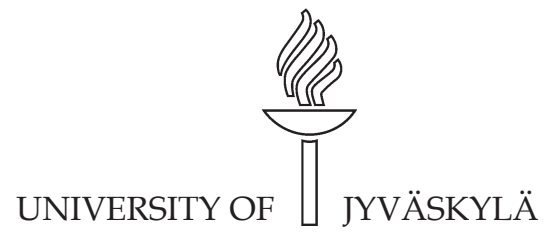

JYVÄSKYLÄ 2013 


\section{Oscillations of Dynamical Systems Applied in Drilling}

Analytical and Numerical Methods 
Maria Kiseleva

\section{Oscillations of Dynamical Systems Applied in Drilling}

Analytical and Numerical Methods

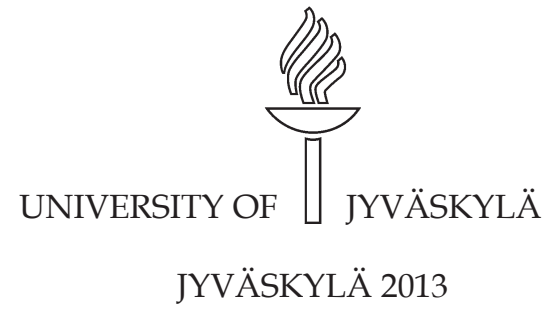


Editors

Timo Männikkö

Department of Mathematical Information Technology, University of Jyväskylä Pekka Olsbo, Ville Korkiakangas

Publishing Unit, University Library of Jyväskylä

URN:ISBN:978-951-39-5519-9

ISBN 978-951-39-5519-9 (PDF)

ISBN 978-951-39-5518-2 (nid.)

ISSN 1456-5390

Copyright (C 2013, by University of Jyväskylä

Jyväskylä University Printing House, Jyväskylä 2013 


\author{
ABSTRACT \\ Kiseleva, Maria \\ Oscillations of Dynamical Systems Applied in Drilling: Analytical and Numerical \\ Methods \\ Jyväskylä: University of Jyväskylä, 2013, 68 p.(+included articles) \\ (Jyväskylä Studies in Computing \\ ISSN 1456-5390; 181) \\ ISBN 978-951-39-5518-2 (nid.) \\ ISBN 978-951-39-5519-9 (PDF) \\ Finnish summary \\ Diss.
}

This work is devoted to the study of electromechanical models of induction motorpowered drilling systems. This is a current issue, as drilling equipment failures cause significant time and expenditure losses for drilling companies. Although there are many papers devoted to the investigation of these systems, equipment failures still occur frequently in the drilling industry.

In this study, we continue investigations begun by researchers from the Eindhoven University of Technology, who introduced an experimental model of a drilling system. The model consists of two discs connected to each other by a steel string that experiences purely torsional deformation. The upper disc is connected to the driving part. The lower disc, representing the bottom end of the drill-string, experiences friction torque caused mainly by interaction with the shale. The key idea of the present study that distinguishes it from the previous model was the introduction of more complex equations of the driving part, in particular, considerations of the induction motor.

Towards this end, two new mathematical models are considered. The first is a simplified one, its prototype being an electric hand drill. In this case it is assumed that the drill string is absolutely rigid and the friction torque acting on the lower part of the drill-string has asymmetric characteristics of the Coulomb type. The qualitative analysis of this model made it possible to obtain parameters on permissible loads (i.e., permissible values of the friction torque) in case the system remained in operational mode after the shale's type changes. Using computer modeling, analysis of sudden load appearance was also performed.

The second mathematical model focuses on the torsional deformation of the drill during operation. For the friction torque with Coulomb type asymmetric characteristic, local analysis of the system is provided. The author carried out computer modeling of the friction model created by the researches at the University of Eindhoven. In this model, we found an interesting effect represented by hidden stick-slip oscillations.

The results of the study have been published in 11 papers.

Keywords: drilling systems, induction motor, friction torque, limit load problem 
Author

Supervisors

Reviewers

Opponent
Maria Kiseleva

Department of Mathematical Information Technology University of Jyväskylä, Finland

Faculty of Mathematics and Mechanics

Saint-Petersburg State University, Russia

Docent Nikolay Kuznetsov

Department of Mathematical Information Technology, University of Jyväskylä, Finland

Professor Gennady A. Leonov

Faculty of Mathematics and Mechanics

Saint-Petersburg State University, Russia

Professor Pekka Neittaanmäki

Department of Mathematical Information Technology, University of Jyväskylä, Finland

Professor Alexey Matveev

School of Electrical Engineering \& Telecommunications University of New South Wales, Australia

Faculty of Mathematics and Mechanics

Saint-Petersburg State University, Russia

Professor Alexander Medvedev

Department of Information Technology

Uppsala University, Sweden

Docent Erkki Laitinen

Department of Mathematical Sciences

University of Oulu, Finland 


\section{ACKNOWLEDGEMENTS}

I would like to express my sincere gratitude to my supervisors Dr. Nikolay Kuznetsov, Prof. Gennady A. Leonov, and Prof. Pekka Neittaanmäki for their guidance and continuous support.

I greatly appreciate the opportunity to participate in the Educational \& Research Double Degree Programme organized by the Department of Mathematical Information Technology (University of Jyväskylä) and the Department of Applied Cybernetics (Saint Petersburg State University). This work was funded by Finnish Doctoral Programme in Computational Sciences (Finland), Saint Petersburg State University (Russia) and Federal Target Programme of Ministry of Education and Science (Russia).

I'm very grateful to the reviewers of the thesis Prof. Alexey Matveev and Prof. Alexander Medvedev.

I would like to thank Prof. Timo Tiihonen for his very important comments and remarks.

This work is dedicated to the loving memory of my parents Olga Ershova and Alexey Kiselev. I would like to extend my deepest thanks to them for making me the person I am today. 


\section{LIST OF FIGURES}

FIGURE 1 Photo of the drilling system ............................................. 10

FIGURE 2 Schematic view of a real drilling rig .................................. 14

FIGURE 3 Photo of an experimental set-up of a drilling system ............. 15

FIGURE 4 Scheme of mathematical model of drilling system................. 16

FIGURE 5 Hand electric drill scheme …........................................ 17

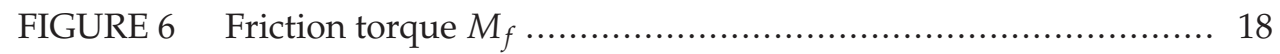

FIGURE 7 Regions of acceptable load: 1 - due to the theorem conditions,

2 -due to computer modeling results .............................. 21

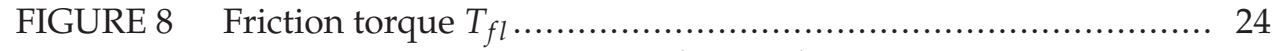

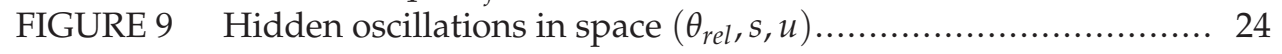

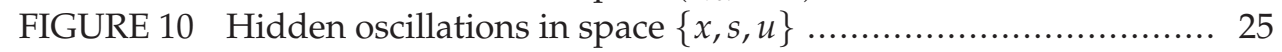

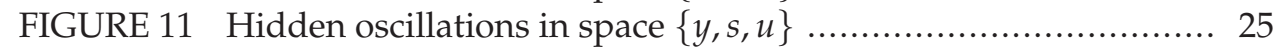

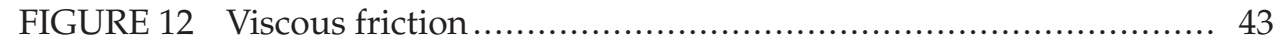

FIGURE 13 Dry friction ...................................................... 44

FIGURE 14 Slope field in the neighborhood of discontinuity surface: the sliding mode .............................................................. 44

FIGURE 15 Slope field in the neighborhood of discontinuity surface: the solution moves away from the discontinuity surface ............... 45

FIGURE 16 Slope field in the neighborhood of discontinuity surface: tra-

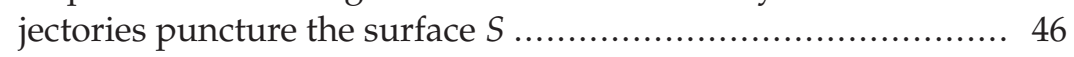

FIGURE 17 The solution goes from one side of the surface $S$ to its other side 48

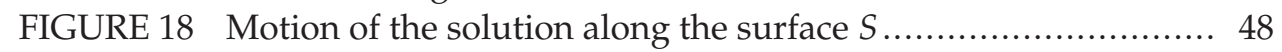

FIGURE 19 The vector fields $F_{1}$ and $F_{2}$ near a stable sliding region $\hat{\Sigma} \ldots \ldots \ldots . . .51$

FIGURE 20 Some trajectories corresponding to the vector fields $F_{1}$ and $F_{2}$

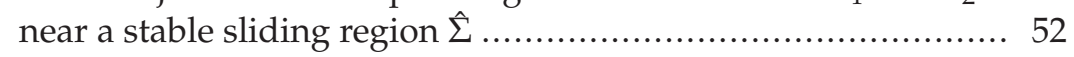

FIGURE 21 Different regions that the state space is divided into in a neigh-

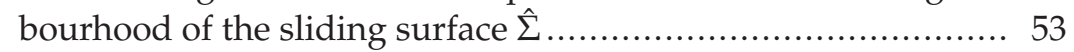

FIGURE 22 Numerical modelling of the Watt governor without using special methods for systems with discontinuous right-hand side.... 56

FIGURE 23 Numerical modelling of the Watt governor with help of the event-driven simulation method. .................................... 56

FIGURE 24 Wound rotor of induction motor: 1 - the first coil with the current $i_{1}, 2$ - the second coil with the current $i_{2}, 3$ - the third coil with the current $i_{3}, 4-$ slip rings, 5 - rotor shaft ............... 58 


\title{
CONTENTS
}

\author{
ABSTRACT \\ ACKNOWLEDGEMENTS \\ LIST OF FIGURES \\ CONTENTS \\ LIST OF INCLUDED ARTICLES
}

1 INTRODUCTION AND THE STRUCTURE OF THE WORK ................ 9

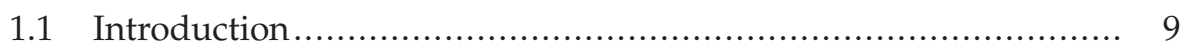

1.2 Methods of investigation ............................................ 10

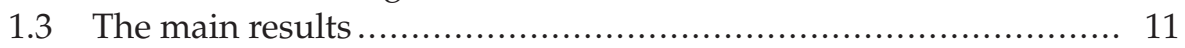

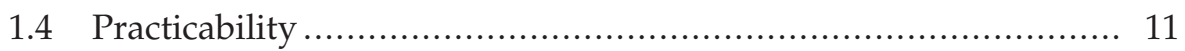

1.5 Included articles ............................................................... 11

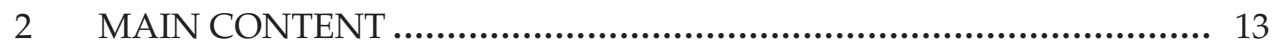

$2.1 \quad$ Real drilling systems...................................................... 13

2.2 A simple mathematical model of a drilling system actuated by induction motor. Limit load problem......................................... 14

2.3 A double-mass mathematical model of a drilling system actuated by an induction motor .............................................. 22

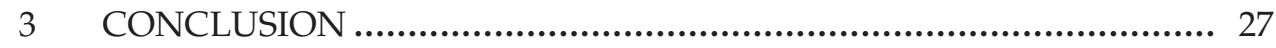

YHTEENVETO (FINNISH SUMMARY) ............................................ 28

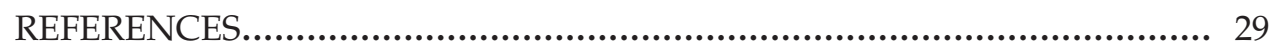

APPENDIX 1 LYAPUNOV FUNCTIONS METHOD .............................. 40

APPENDIX 2 DIFFERENTIAL INCLUSIONS AND FILIPPOV DEFINITION ..................................................................... 43

APPENDIX 3 NUMERICAL METHODS OF STABILITY INVESTIGATION OF DISCONTINUOUS SYSTEMS.................................... 50

APPENDIX 4 MATHEMATICAL MODEL OF INDUCTION MOTOR ........ 57

APPENDIX 5 PROOF OF THE THEOREM ON LOCAL STABILITY .......... 61

APPENDIX 6 COMPUTER ASSISTED MODELLING OF TWO-MASS MATHEMATICAL MODEL OF THE DRILLING SYSTEM(MATLAB IMPLEMENTATION) ............................................... 63

INCLUDED ARTICLES 


\section{LIST OF INCLUDED ARTICLES}

PI G.A. Leonov, M.A. Kiseleva. Stability of Electromechanical Models of Drilling Systems under Discontinuous Loads. Doklady Physics, Vol. 57, No. 5, pp. 206-209, 2012.

PII M.A. Kiseleva, N.V. Kuznetsov, G.A. Leonov, P. Neittaanmäki. Drilling Systems Failures and Hidden Oscillations. IEEE 4th International Conference on Nonlinear Science and Complexity, NSC 2012 - Proceedings, pp. 109-112, 2012.

PIII G.A. Leonov, M.A. Kiseleva, N.V. Kuznetsov, P. Neittaanmäki. Hidden Oscillations in Drilling Systems: Torsional Vibrations. Journal of Applied Nonlinear Dynamics, Vol. 2, No. 1, pp. 83-94, 2013.

PIV M.A. Kiseleva, N.V. Kuznetsov, G.A. Leonov, P. Neittaanmäki. Hidden Oscillations in Drilling Systems Actuated by Induction Motor. Periodic Control Systems, Vol. 5, No. 1, pp. 86-89, (5th IFAC International Workshop on Periodic Control Systems, Caen, France), 2013.

PV M.A. Kiseleva, G.A. Leonov, N.V. Kuznetsov, P. Neittaanmäki. Drilling Systems: Stability and Hidden Oscillations. Discontinuity and Complexity in Nonlinear Physical Systems. Series: Nonlinear Systems and Complexity, Vol. 6, pp. 287-304, 2014. 


\section{INTRODUCTION AND THE STRUCTURE OF THE WORK}

\subsection{Introduction}

One of the most common problems in the drilling industry is the breakdown of drill systems (see Fig. $1^{1}$ ). From both a practical and theoretical perspective, the study of the transient processes in drilling equipment is very important.

Breakdowns occur frequently in the oil and gas industry, which causes significant losses of time and expenditure. Of special interest is the cessation of normal performance in the drill string caused by sudden increase in load. Given the substantial losses caused by each incident of drill failure, the study of drilling systems is crucial to minimize equipment failures. According to the statistics provided in (Horbeek et al., 1995; Shokir, 2004; Vaisberg et al., 2002), in 1985, 45 \% of all rigs' failures were directly related to the drill string. Currently, each drilling rig failure leads to expensive losses. Approximately one out of every seven rigs will experience drill string failure of some sort. Even with all the research devoted to reducing the failures of drill strings (Besselink et al., 2011; Mihajlović et al., 2006, 2007; Germay et al., 2009; Viguié et al., 2009), the data mentioned above shows that drill strings still break frequently. Thus, the study of transient processes appearing in drilling rigs is relevant to the modern application of drilling theory.

This work's focus is in the study of the dynamics of more thorough models of drilling systems actuated by an electric induction motor.

The goal of this work is to create and to study mathematical models of the drilling systems with more emphasis and consideration of the electrical drive operation in comparison with earlier investigations. These newly refined models include an investigation of the influence of different loads on those models with the help of analytical and numerical methods of investigation of dynamical systems,

1 Joshua Doubek (Own work), via Wikimedia Commons. 2013. upright oil derrick in the Williston Basin North Dakota. URL:http:/ / upload.wikimedia.org/wikipedia/commons/ 1/1f/Upright_oil_derrick.JPG. [Online; accessed 09-September-2013] 


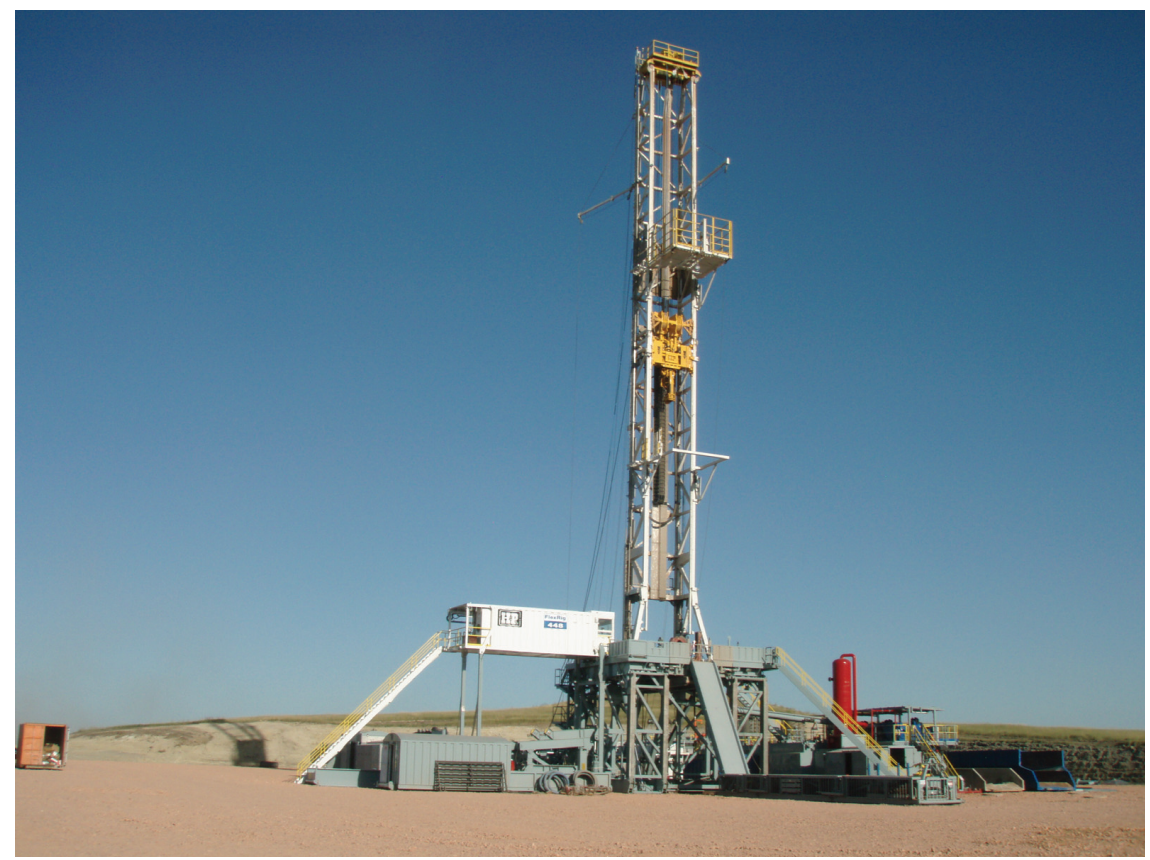

FIGURE 1 Photo of the drilling system

modern computational tools, and specialized mathematical software packages.

The stability criterion developed in this work allows for calculation of the range of permissible loads for the drill when the type of shale changes. In cases with a double-mass model of a drilling system, the so-called "hidden oscillations" have been detected. The breakdown of the drilling equipment may be caused by the presence of such oscillations, but these oscillations cannot be detected by the transient process, which begins in a state of a stable equilibrium.

\subsection{Methods of investigation}

This work uses both analytical and numerical methods of investigation of dynamical systems. All models included have been described using differential equations with discontinuous right-hand sides. For this purpose, the methods of investigation of differential equations with discontinuous right-hand sides were used, including the Filippov definition (see Appendix 2). In order to understand the global stability of these systems, it was necessary to investigate the behavior of their trajectories in the regions of continuity. This approach permitted the use of the Lyapunov functions method (see Appendix 1) to investigate ordinary differential equations with continuous right-hand sides. Regarding computer modeling, in order to avoid computational errors, it is of utmost importance to correctly define the behavior of the system in the neighborhood of the disconti- 
nuity surface. This method of correct computer modeling is based on Filippov definition and is described in Appendix 3, the MATLAB code of the method is presented in Appendix 6.

\subsection{The main results}

- A mathematical model of a drilling system whose drill string is rigid and is actuated by an induction motor is developed (PI; PV).

- An appropriate load characteristic representing non-symmetrical dry friction is introduced. The limit load problem is solved for the model containing this type of friction (PI; PV).

- A double-mass mathematical model of a drilling system actuated by an induction motor is developed. Local analysis of the system with Coulomb type asymmetric friction torque is provided (PII; PIII; PIV; PV).

All analytical results developed in the study are rigorously proven. For the computer modeling, methods specifically designed for the integration of differential equations with discontinuous right-hand sides were used in order to avoid computational errors. The results obtained are in correlation with the results of other researchers, in particular from Eindhoven University of Technology.

\subsection{Practicability}

The models obtained allow for increased effectiveness in the analysis of the performance of the drilling systems. Engineers may use the regions of stability of the drilling models to minimize failures in drilling rigs. Furthermore, it is demonstrated that the models may experience hidden stable oscillations which co-exist with a stable equilibrium state for certain systems. It is possible to miss those hidden oscillations during computer modeling and reach a wrong conclusion about the global stability of a system, which can result in drilling system failure. To avoid this, it is necessary to use special approaches when investigating such drilling systems.

\subsection{Included articles}

The main results were published in the five included articles. In articles PI-PV, the formulation of the problem belongs to the co-authors. In article PI, the author obtained estimates of the limiting value of the permissible rapidly alternating load for the model of a drilling system experiencing non-symmetrical dry friction. In articles (PII; PIII; PIV), a new double-mass drilling system model ac- 
tuated by an induction motor is introduced. During numerical analysis of the models, hidden oscillations were found by the author. In PV, the author studied different mathematical models of the drilling systems. Preliminary summary of the dissertation material has been presented in (Kiseleva, 2013).

The results of this study were also published in (Kiseleva, 2013, 2012a; Kiseleva and Leonov, 2012; Kiseleva, 2012b, 2011; Kiseleva et al., 2010) reported at many international conferences: 5th IFAC International Workshop on Periodic Control Systems "PSYCO-2013" (Caen, France), "International Student Conference on Automation \& Control" (Saint-Petersburg, Russia), "4th IEEE International Conference on Nonlinear Science and Complexity" (Budapest, Hungary -2012), XII International Conference "Stability and Oscillations of Nonlinear Control Systems", Pyatnitskiy conference (Moscow, Russia - 2012), "Sixth Polyakhov Readings" (Saint Petersburg, Russia - 2012), 4th All-Russian Multi-Conference on Control Problems "MKPU-2011" (Divnomorskoe, Russia - 2011), International Workshop "Mathematical and Numerical Modeling in Science and Technology" (Finland, Jyväskylä - 2010) and at the seminars of the department of Applied Cybernetics (Saint Petersburg State University, Russia 2009 - 2013) and the department of Information Technology (University of Jyväskylä, Finland 2009-2013). 


\section{MAIN CONTENT}

\subsection{Real drilling systems}

It is necessary to know how the real drilling equipment used in the oil and gas industry works if the mathematical models of the drilling systems are to be understood.

The rotary type drilling systems are used for drilling wells for exploration and production of oil and gas (Mihajlović, 2005). A schematic view of a rotary drilling system is shown in Fig. 2 (Leine, 2000). A rock-cutting tool called drillbit creates a borehole in the drilled surface. The bit represents a short heavy segment containing a cutting device at the free end (Tucker and Wang, 1999), which is driven by torque created at the surface by a motor through a mechanical transmission box. The motor (large disc) drives the rotary table via transmission. The rotary table acts as a kinetic energy storage unit. A drill-string transmits this energy from the surface to the bit. The drill-string consists mainly of drill pipes that can be up to $8 \mathrm{~km}$ long. The lowest part of the drill-string is the BottomHole-Assembly (BHA). The BHA can reach several hundred meters in length , and consists of drill collars and the bit.

A real drill-string undergoes various types of vibrations during the drilling process (Mihajlović, 2005; Mihajlović et al., 2007; Jansen, 1991; Leine, 2000; Leine and Van Campen, 2005; Van den Steen, 1997): torsional (rotational), bending (lateral), axial (longitudinal) and hydraulic vibrations. Torsional vibrations are caused by nonlinear interaction between the bit and the shale or the drill-string and the borehole wall. Pipe eccentricity is generally the cause of bending vibrations, which lead to centripetal forces during the rotation. Axial vibrations are caused by the bouncing of the drilling bit on the shale during operation. Hydraulic vibrations are found in the circulation system, stemming from the pump pulsations. There has already been extensive research on the subject of frictioninduced torsional vibrations in the drill-string systems. Much of the research considers vibrations in the drill-string systems(Brett, 1992; Germay, 2002; Jansen and Van den Steen, 1995; Kreuzer and Kust, 1996a,b; Keuzer and Kust, 1997; 


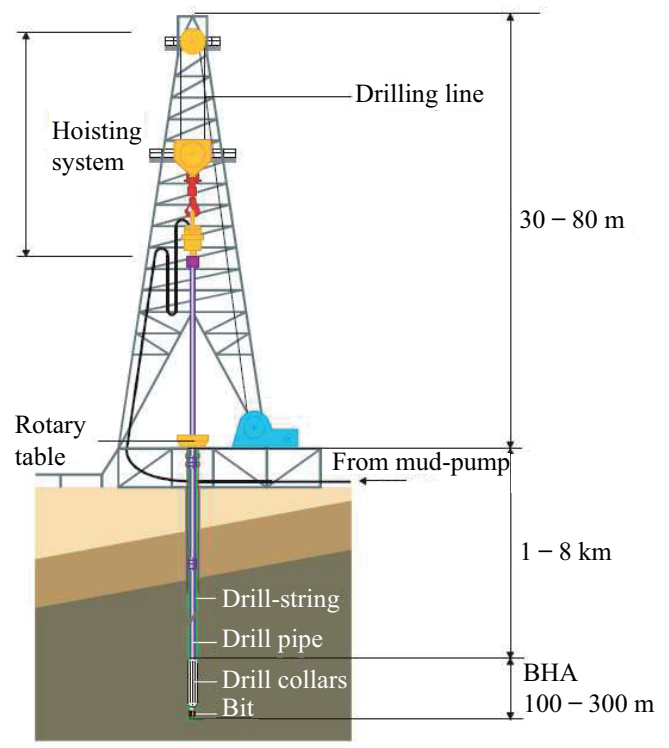

FIGURE 2 Schematic view of a real drilling rig

Kust, 1998; Kyllingstad and Halsey, 1988; Jansen, 1991; Leine, 2000; Leine and Van Campen, 2005; Mihajlović et al., 2005, 2004b,a; Van den Steen, 1997). It is generally concluded that torsional vibrations are the result of negative damping in the friction force at the point between the bit and the borehole (see, for example, (Brett, 1992; Kreuzer and Kust, 1996a; Mihajlović et al., 2004b)). This conclusion is supported by additional evidence from various other investigations (Brett, 1992; Leine, 2000; Leine and Van Campen, 2005; Mihajlović et al., 2005, 2004b,a; Van den Steen, 1997). With those conclusions in mind, a control strategy is suggested in (Jansen and Van den Steen, 1995) that torsional vibrations the in drill-string systems should be avoided. It should be noted that Germay (Germay, 2002) and Richard et al. (Richard et al., 2004) concluded that the interaction between torsional and axial dynamics of the system may cause torsional vibrations in the drilling systems. Such interaction effectively leads to the Stribeck effect, according to these authors.

Only one type of vibration - torsional - is considered in this work, since it is usually regarded as one of the most damaging types of vibration (Omojuwa et al., 2011; Rajnauth, 2003).

\subsection{A simple mathematical model of a drilling system actuated by induction motor. Limit load problem.}

The goal of this study was the development of mathematical models of drilling rigs with an induction motor as the drive (see, e.g. (Hild, 1934; Staege, 1936; Hall 


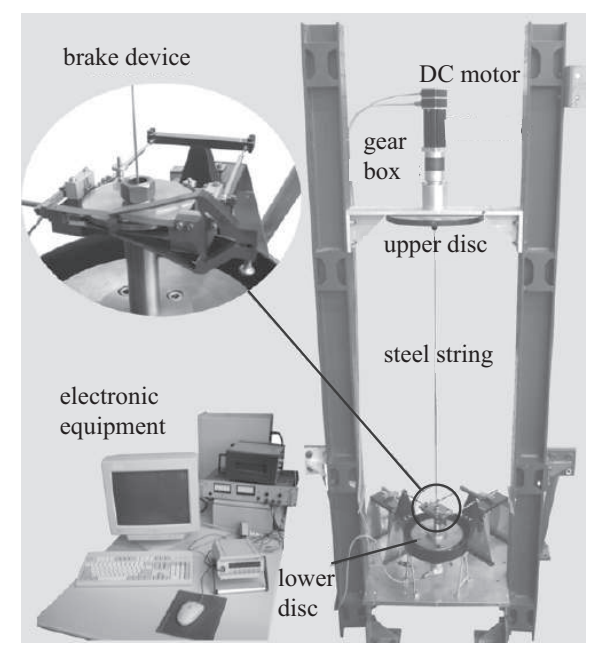

FIGURE 3 Photo of an experimental set-up of a drilling system

and Shumway, 2009)), and to study the effect of different loads on a number of models. First, the model which served as the motivation for this research will be considered.

An experimental rotor dynamic set-up was studied in the articles by $\mathrm{Ni}$ jmeijer, van de Wouw, Mihajlović (De Bruin et al., 2009; Mihajlović et al., 2006; Mihajlović, 2005) (see Fig. 3, (De Bruin et al., 2009)). Its configuration can be recognized in the structure of the drilling systems. The set-up mainly consists of an upper disc actuated by the driving part, a flexible steel string connecting it with a lower disc, and a brake device. The upper and lower discs revolve on their axes (see Fig. 4 (Mihajlović et al., 2006)). The brake device serves as a model for friction force acting on the lower disc.

The following differential equations of rotation of the upper and lower discs are presented ${ }^{1}$ :

$$
\begin{aligned}
& J_{u} \ddot{\theta}_{u}(t)+k_{\theta}\left(\theta_{u}(t)-\theta_{l}(t)\right)+b\left(\dot{\theta}_{u}(t)-\dot{\theta}_{l}(t)\right)+T_{f u}\left(\dot{\theta}_{u}(t)\right)-k_{m} u=0, \\
& J_{l} \ddot{\theta}_{l}(t)-k_{\theta}\left(\theta_{u}(t)-\theta_{l}(t)\right)-b\left(\dot{\theta}_{u}(t)-\dot{\theta}_{l}(t)\right)+T_{f l}\left(\dot{\theta}_{l}(t)\right)=0 .
\end{aligned}
$$

Here $\theta_{u}$ and $\theta_{l}$ represent the angular displacements of the upper and lower discs, respectively. $J_{u}$ and $J_{l}$ are inertia torques, $k_{\theta}, b, k_{m}$ are non-negative coefficients, $u$

1 The derivation of this model can be explained in the following way (Kiseleva, 2013; Leonov et al., 2014):

$$
\begin{aligned}
& J_{u} \ddot{\theta}_{u}=M_{u}-M_{r u}, \\
& J_{l} \ddot{\theta}_{u}=M_{l}-M_{r l},
\end{aligned}
$$

where $M_{u}, M_{l}$ are rotation torques, $M_{r u}, M_{r l}$ are resistance torques. Here

$$
\begin{aligned}
& M_{u}=k_{m} u-T_{f u}\left(\dot{\theta}_{u}\right), \\
& M_{l}=M_{r u}=k_{\theta}\left(\theta_{u}-\theta_{l}\right)+b\left(\dot{\theta}_{u}-\dot{\theta}_{l}\right), \\
& M_{r l}=T_{f l}\left(\dot{\theta}_{l}\right),
\end{aligned}
$$

and $M_{u}$ is a drive part torque. Later on, when considering the models actuated by an induction motor, this torque will undergo changes. 


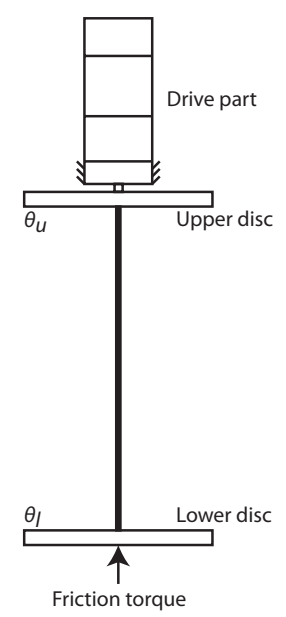

FIGURE 4 Scheme of mathematical model of drilling system

is a constant input voltage, $T_{f u}\left(\dot{\theta}_{u}\right)$ and $T_{f l}\left(\dot{\theta}_{l}\right)$ are friction torques acting on the upper and lower discs.

This double-mass model allows for convenient analysis of the drilling system model. However, full dynamics consideration of the electric motor which actuates the upper disc in this system is lacking.

Significant results were achieved by the group from Saint Petersburg State University lead by Prof. Leonov in the study of mathematical models of electrical machines. New mathematical models of electrical machines were developed in (Leonov and Kondrat'eva, 2009; Solovyeva, 2011; Zaretskiy, 2011). A new method of nonlocal reduction is suggested, allowing improved estimates of the limit loads for the models considered. These models take into account the dynamics of the rotor of electrical machines and can be reduced to some other common models, such as a motor with squirrel-cage rotor (Leonov et al., 2014). Simple differential equations are used to describe the derived models, which allows for the in-depth qualitative study of such models. This ensures that the implementation of these equations in the mechanical model will result in more precise analysis (both analytical and numerical).

Here, for the both types of new models of the drilling systems, the model of induction motor offered in (Leonov et al., 2014) will be used.

In PI, a simple electro-mechanical model described, and the limit load problem is solved for that model actuated by an induction motor. The behavior of this model differs little from that of an ordinary drill (see Fig. $5^{2}$ ).

Due to the short drill-string length, the torsional deformation relative to the rotation angle of such a drill is extremely small . It can thus be assumed that the

$2 \quad$ By Kosiarz-PL (Own work by uploader) [GFDL (http:/ / www.gnu.org/copyleft/fdl.html), CC-BY-SA-3.0 (http://creativecommons.org/licenses/by-sa/3.0/)], via Wikimedia Commons. 2013. Operating a pistol-grip drill - scheme. URL:http://upload.wikimedia. org/wikipedia/commons/thumb/0/06/Drill_scheme.svg/424px-Drill_scheme.svg.png . [Online; accessed 11-October-2013] 


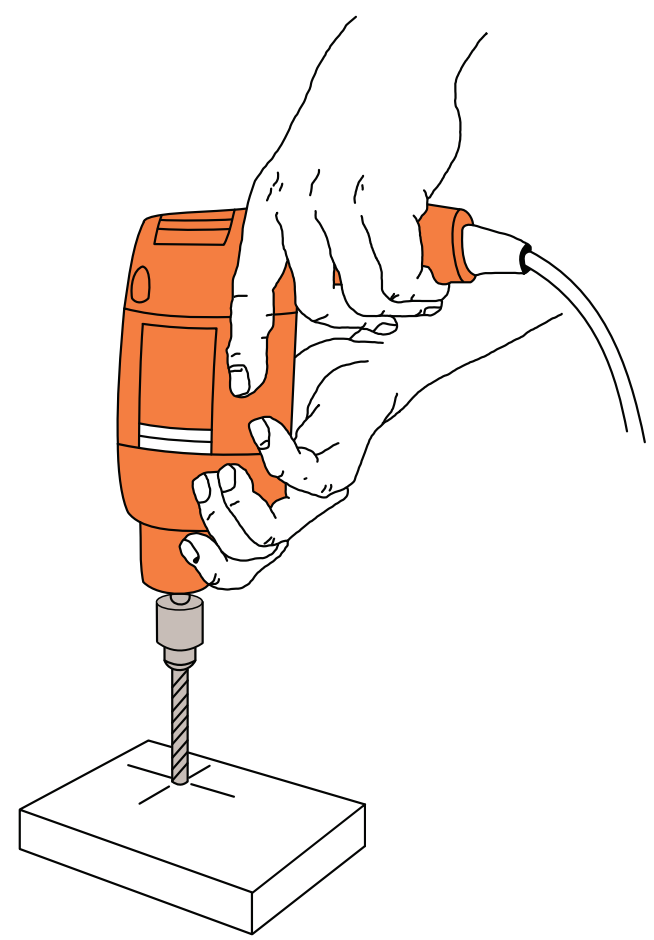

FIGURE 5 Hand electric drill scheme

drill-string in this scenario is absolutely rigid. Assume that it is stiffly connected to the rotor which rotates under the influence of magnetic field created by the stator of the induction motor. The resistance torque during the drilling process defines the interaction of the drill with the shale. Rapidly shifting loads are experienced by the system when the drill bit comes into contact with the bedrock. The crucial aspect of the study is the behavior of the induction motor when the friction torque suddenly experiences an abrupt change.

Consider the equations of the induction motor to be the equations of the electromechanical model of the drilling system, (see Appendix 4, (Leonov et al., 2014); as well as other sorts of induction motors (Leonhard, 2001; Khalil and Grizzle, 2002; PI; PV) may also be considered) supplemented with the resistance torque $M_{f}$ :

$$
\begin{aligned}
& L i_{1}+R i_{1}=-n B S \dot{\theta} \cos \left(\frac{\pi}{2}-\theta\right) \\
& L i_{2}+R i_{2}=-n B S \dot{\theta} \cos \left(\frac{\pi}{2}-\theta-\frac{2 \pi}{3}\right), \\
& L i_{3}+R i_{3}=-n B S \dot{\theta} \cos \left(\frac{\pi}{2}-\theta-\frac{4 \pi}{3}\right), \\
& I \ddot{\theta}=n B S \sum_{k=1}^{3} i_{k} \cos \left(\frac{\pi}{2}-\theta-\frac{2(k-1) \pi}{3}\right)+M_{f}\left(\omega_{m f}+\dot{\theta}\right) .
\end{aligned}
$$

In this equation, $\theta$ is the drill's angle of rotation about the magnetic field rotating with the constant angular speed $\omega_{m f}, i_{1}, i_{2}, i_{3}$ are currents in the rotor coils, $R$ is the resistance of the coils, $L$ is the inductance of the coils, $B$ is the induction of 


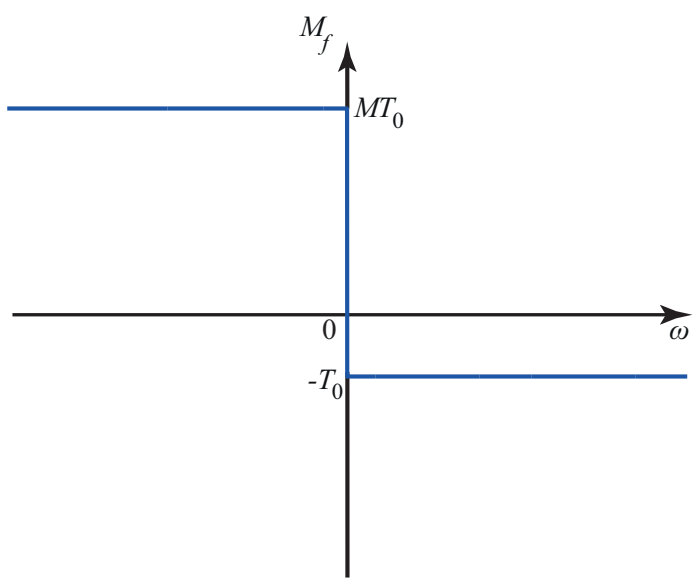

FIGURE 6 Friction torque $M_{f}$

magnetic field, $n$ is the amount of winds in every coil, $S$ is the area of one coil wind, $I$ is the inertia torque of the drill, $\omega=\dot{\theta}+\omega_{m f}$ is the angular velocity of the drill rotation with respect to a fixed coordinate system. The resistance torque $M_{f}$ is assumed to be of the Coulomb type. Unlike the classic Coulomb friction law with symmetrical discontinuous characteristics, however, friction torque $M_{f}$ has non-symmetrical discontinuous characteristics depicted in Fig. 6 (see PI)

$$
M_{f} \in \begin{cases}-T_{0}, & \text { if } \omega>0 \\ {\left[-T_{0}, M T_{0}\right],} & \text { if } \omega=0 \\ M T_{0}, & \text { if } \omega<0\end{cases}
$$

Where $T_{0} \geq 0$, number $M>0$ is assumed to be large enough. The drilling process only takes place when $\omega>0$, reflected in the previous condition. This does not allow for $\omega$ to switch from positive to negative values during the transient process in real systems. The system will only stop when $\omega=0$ for a long enough period of time in these cases, which happen frequently during drilling operations.

Note that in (3) a sign $\in$ of differential inclusion was used. Differential inclusion is directly related to the notion of right-hand discontinuous differential equations. There have been several papers devoted to this subject, such as (Andronov et al., 1981; Barbashin, 1967; Gelig et al., 1978; Neimark, 1972) The works of Filippov (Filippov, 1988, 1985) contain a detailed description of this theory. In (Filippov, 1985), differential equations with single-valued discontinuous righthand sides are considered, a concept of solution is introduced and the basic results of the qualitative theory are proven (see the main notions and approaches in Appendix 2). 
Performing the nonsingular change of variables (Leonov et al., 2014)

$$
\begin{aligned}
& s=-\dot{\theta}, \\
& x=-\frac{2}{3} \frac{L}{n S B} \sum_{k=1}^{3} i_{k} \sin \left(\frac{\pi}{2}-\theta-\frac{2(k-1) \pi}{3}\right), \\
& y=-\frac{2}{3} \frac{L}{n S B} \sum_{k=1}^{3} i_{k} \cos \left(\frac{\pi}{2}-\theta-\frac{2(k-1) \pi}{3}\right)
\end{aligned}
$$

we reduce the system (2) to the following system (PI; PV):

$$
\begin{aligned}
& \dot{s}=a y+\xi(s, y), \\
& \dot{y}=-c y-s-x s, \\
& \dot{x}=-c x+y s,
\end{aligned}
$$

where

$$
a=\frac{3(n S B)^{2}}{2 I L}, \quad c=\frac{R}{L} .
$$

Here variables $x, y$ define the electric values in the rotor windings and the variable $s$ defines the sliding of the rotor. For $\xi(s, y)$, the following Filippov definition is valid:

$$
\xi(s, y)= \begin{cases}\gamma, & \text { if } s=\omega_{m f}, y<-\frac{\gamma}{a} \text { or } s<\omega_{m f} \\ -\gamma M, & \text { if } s=\omega_{m f}, y>\frac{M \gamma}{a} \text { or } s>\omega_{m f} \\ -a y, & \text { if } s=\omega_{m f},-\frac{\gamma}{a} \leq y \leq \frac{M \gamma}{a}\end{cases}
$$

where $\gamma=\frac{T_{0}}{I}$.

Let us introduce the parameter

$$
\gamma_{\max }=\frac{a c \omega_{m f}}{c^{2}+\omega_{m f}^{2}} .
$$

The local analysis of equilibrium states of system (5) shows that for $0 \leq \gamma<\gamma_{\max }$ it has the unique asymptotically stable state of equilibrium.

Indeed, where $\gamma=0$, system (5) has one asymptotically stable equilibrium state $s=0, y=0, x=0$, which occurs when the rotation of the drill with constant angular speed is congruent to the rotation speed of the magnetic field (idle speed operation).

For $\gamma \in\left(0, \gamma_{\max }\right)$ system (5) has one equilibrium state:

$$
s_{0}=\frac{c\left(a-\sqrt{a^{2}-4 \gamma^{2}}\right)}{2 \gamma}, \quad y_{0}=-\frac{\gamma}{a}, \quad x_{0}=-\frac{\gamma s_{0}}{a c},
$$

where $s_{0}$ is the smallest root of the equation

$$
\frac{a c s}{c^{2}+s^{2}}=\gamma \text {. }
$$


In this case, the direction of rotation of the drill and the magnetic field are the same, but the drill rotates with a lower angular speed $s_{0}<\omega_{m f}$.

Assume that there is a sudden change in load at the moment $t=\tau$ from value $\gamma_{0}$ to value $\gamma_{1}$, where $0<\gamma_{0}<\gamma_{1}<\gamma_{\max }$. This occurs at the moment the drill comes in contact with the bedrock. For $\gamma=\gamma_{0}$ the system experiences a unique state of stable equilibrium

$$
s_{0}=\frac{c\left(a-\sqrt{a^{2}-4 \gamma_{0}^{2}}\right)}{2 \gamma_{0}}, \quad y_{0}=-\frac{\gamma_{0}}{a}, \quad x_{0}=-\frac{\gamma_{0} s_{0}}{a c} .
$$

After the transient process, it is essential, that the solution $s(t), x(t), y(t)$ of system (5) with $\gamma=\gamma_{1}$ and the initial data

$$
s(\tau)=\frac{c\left(a-\sqrt{a^{2}-4 \gamma_{0}^{2}}\right)}{2 \gamma_{0}}, \quad y(\tau)=-\frac{\gamma_{0}}{a}, \quad x(\tau)=-\frac{\gamma_{0} s_{0}}{a c}
$$

tends to the equilibrium state

$$
s_{1}=\frac{c\left(a-\sqrt{a^{2}-4 \gamma_{1}^{2}}\right)}{2 \gamma_{1}}, \quad y_{1}=-\frac{\gamma_{1}}{a}, \quad x_{1}=-\frac{\gamma_{1} s_{1}}{a c}
$$

when $t \rightarrow+\infty$.

The following theorem is proved in the included articles (PI; PV).

Theorem 1 Let the following conditions be fulfilled

$$
\begin{aligned}
& \gamma_{0}<\gamma_{\max }, \\
& \gamma_{1}<\min \left\{\gamma_{\max }, 2 c^{2}\right\} \\
& \frac{\left(\gamma_{1}-\gamma_{0}\right)^{2}}{2 c^{2}} s_{0}^{2}+\frac{\left(\gamma_{1}-\gamma_{0}\right)^{2}}{2} \leq \int_{s_{0}}^{\omega_{m f}}\left(-\frac{\gamma_{1}}{c} s^{2}+a s-c \gamma_{1}\right) d s+\frac{(1+M)^{2}}{2} \gamma_{1}^{2} .
\end{aligned}
$$

Then the solution of system (5) with $\gamma=\gamma_{1}$ and the initial data

$$
s(\tau)=\frac{c\left(a-\sqrt{a^{2}-4 \gamma_{0}^{2}}\right)}{2 \gamma_{0}}, \quad y(\tau)=-\frac{\gamma_{0}}{a}, \quad x(\tau)=-\frac{\gamma_{0} s_{0}}{a c}
$$

tends to an equilibrium state of this system when $t \rightarrow+\infty$.

The proof is based on building the following Lyapunov function (see Appendix 1) within the region of continuity:

$$
V(x, y, s)=\frac{a^{2}}{2}\left(x+\frac{\gamma_{1}}{a c} s\right)^{2}+\frac{1}{2}\left(a y+\gamma_{1}\right)^{2}+\int_{s_{1}}^{s}\left(-\frac{\gamma_{1}}{c} s^{2}+a s-c \gamma_{1}\right) d s .
$$

The corollaries formulated below follow naturally from Theorem 1. 
Corollary 1 Let the following conditions be fulfilled

$$
\begin{gathered}
\gamma_{0}<\gamma_{\max }, \\
\gamma_{1}<\min \left\{\gamma_{\max }, 2 c^{2}\right\}, \\
3\left(M^{2}+2 M\right) \gamma_{1}^{2}-8 c^{2} \gamma_{1}+3 a c^{2} \geq 0 .
\end{gathered}
$$

Then the solution of system (5) with $\omega_{m f}=c, \gamma=\gamma_{1}$ and the initial data

$$
s(\tau)=\frac{c\left(a-\sqrt{a^{2}-4 \gamma_{0}^{2}}\right)}{2 \gamma_{0}}, \quad y(\tau)=-\frac{\gamma_{0}}{a}, \quad x(\tau)=-\frac{\gamma_{0} s_{0}}{a c}
$$

tends to the equilibrium state of this system when $t \rightarrow+\infty$.

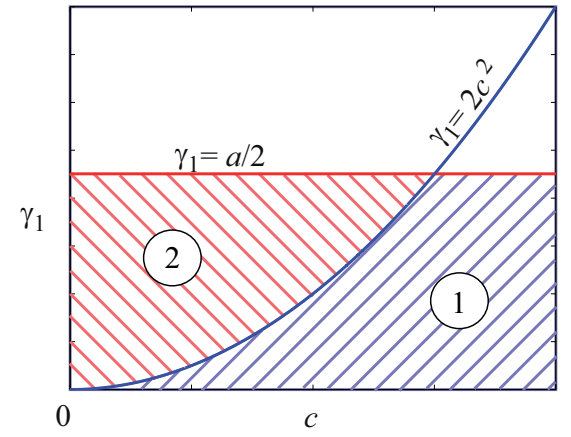

FIGURE 7 Regions of acceptable load: 1 - due to the theorem conditions, 2 - due to computer modeling results

Corollary 2 Let $M$ be sufficiently large positive number, $\omega_{m f}=c, \gamma_{0}=0$ and

$$
\gamma_{1}<\min \left\{\frac{a}{2}, 2 c^{2}\right\}
$$

Then the solution of system (5) with $\gamma=\gamma_{1}$ and the initial data

$$
s(\tau)=0, \quad y(\tau)=0, \quad x(\tau)=0
$$

tends to the equilibrium state of this system when $t \rightarrow+\infty$.

In the case when

$$
2 c^{2}<\frac{a}{2} \text { for } \gamma_{1} \in\left(2 c^{2}, \frac{a}{2}\right)
$$

(i.e., condition (6) is not fulfilled), the computer modeling of system (5) was carried out (area 2 on Fig. 7, see PI) and it demonstrated that the corollary statement remains valid. The computer modeling applies the specialized methods for systems with right-hand discontinuity (see Appendix 3). 


\subsection{A double-mass mathematical model of a drilling system actu- ated by an induction motor}

In PII-PV, an electromechanical model of an induction motor-powered drilling system is introduced, and the torsional deformation of the drill string during the operation is studied. Let us extend the double-mass model of a drilling system considered above by adding the equations of an induction motor (see Appendix 4, (Leonov et al., 2014)):

$$
\begin{aligned}
& L \dot{i_{1}}+R i_{1}=-n B S \dot{\theta_{u}} \cos \left(\frac{\pi}{2}-\theta_{u}\right), \\
& L \dot{i_{2}}+R i_{2}=-n B S \dot{\theta_{u}} \cos \left(\frac{\pi}{2}-\theta_{u}-\frac{2 \pi}{3}\right), \\
& L \dot{i_{3}}+R i_{3}=-n B S \dot{\theta_{u}} \cos \left(\frac{\pi}{2}-\theta_{u}-\frac{4 \pi}{3}\right), \\
& J_{u} \ddot{\theta}_{u}+k_{\theta}\left(\theta_{u}-\theta_{l}\right)+b\left(\dot{\theta}_{u}-\dot{\theta}_{l}\right)-n B S \sum_{k=1}^{3} i_{k} \cos \left(\frac{\pi}{2}-\theta_{u}-\frac{2(k-1) \pi}{3}\right)=0, \\
& J_{l} \ddot{\theta}_{l}-k_{\theta}\left(\theta_{u}-\theta_{l}\right)-b\left(\dot{\theta}_{u}-\dot{\theta}_{l}\right)+T_{f l}\left(\omega_{m f}+\dot{\theta}_{l}\right)=0 .
\end{aligned}
$$

Here $\theta_{u}, \theta_{l}$ are angular displacements of the rotor and the lower disc relative to the rotating magnetic field, $\omega_{m f}$ is a rotation speed of the magnetic field, $T_{f l}\left(\omega_{m f}+\right.$ $\left.\dot{\theta}_{l}\right)$ is a friction torque.

Performing the nonsingular change of variables

$$
\begin{aligned}
& s=-\dot{\theta}_{u}, \\
& x=-\frac{2}{3} \frac{L}{n S B} \sum_{k=1}^{3} i_{k} \sin \left(\frac{\pi}{2}-\theta_{u}-\frac{2(k-1) \pi}{3}\right), \\
& y=-\frac{2}{3} \frac{L}{n S B} \sum_{k=1}^{3} i_{k} \cos \left(\frac{\pi}{2}-\theta_{u}-\frac{2(k-1) \pi}{3}\right), \\
& u=-\dot{\theta}_{l}, \\
& \theta_{\text {rel }}=\theta_{u}-\theta_{l},
\end{aligned}
$$

we obtain the system

$$
\begin{aligned}
& \dot{x}=-c x+y s, \\
& \dot{y}=-c y-s-x s, \\
& \dot{\theta}_{r e l}=u-s, \\
& \dot{s}=\frac{k_{\theta}}{J_{u}} \theta_{r e l}+\frac{b}{J_{u}}(u-s)+\frac{a}{J_{u}} y, \\
& \dot{u}=-\frac{k_{\theta}}{J_{l}} \theta_{r e l}-\frac{b}{J_{l}}(u-s)+\frac{1}{J_{l}} T_{f l}\left(\omega_{m f}-u\right) .
\end{aligned}
$$

Here $a=\frac{3(n S B)^{2}}{2 L}, c=\frac{R}{L}$. 
Consider the case when the friction force has non-symmetrical characteristics considered above:

$$
T_{f l}\left(\omega_{l}\right) \in \begin{cases}\gamma, & \text { if } \omega_{l}>0 \\ {[-M \gamma, \gamma],} & \text { if } \omega_{l}=0 \\ -M \gamma, & \text { if } \omega_{l}<0\end{cases}
$$

where $\omega_{l}=\omega_{m f}-u$. Here $M, \gamma>0$.

The results of the local analysis of the system are formulated in the following theorem:

Theorem 2 For

$$
b=0, \quad 0<\gamma<\gamma_{\max }=\frac{a c \omega_{m f}}{c^{2}+\omega_{m f}{ }^{2}}
$$

the system (7) has one asymptotically stable equilibrium state:

$$
s_{0}=u_{0}, \quad x_{0}=-\frac{\gamma s_{0}}{a c}, \quad y_{0}=-\frac{\gamma}{a}, \quad \theta_{r e l 0}=\frac{\gamma}{k_{\theta}},
$$

where $s_{0}$ is the smallest root of the equation

$$
\frac{a c s}{c^{2}+s^{2}}=\gamma .
$$

Appendix 5 contains the proof of this theorem, which is similar to the proof of the theorem described in Appendix 1.

During the numerical analysis of the system, stable operation modes of the drilling system were found, along with modes where the drill gets stuck. Let us consider a more complex friction model. Assume that the friction torque is as follows (see Fig. 8, (De Bruin et al., 2009))

$$
\begin{gathered}
T_{f l}\left(\omega_{l}\right) \in \begin{cases}T_{c l}\left(\omega_{l}\right) \operatorname{sign}\left(\omega_{l}\right), & \text { if } \omega_{l} \neq 0 \\
{\left[-T_{s l}, T_{s l}\right],} & \text { if } \omega_{l}=0,\end{cases} \\
T_{c l}\left(\omega_{l}\right)=T_{f l}+\left(T_{s l}-T_{f l}\right) e^{-\mid \frac{\omega_{l}}{\omega_{s l}} \delta_{s l}}+b_{l}\left|\omega_{l}\right|,
\end{gathered}
$$

where $T_{s l}, T_{f l}, \omega_{s l}, \delta_{s l}$ and $b_{l}$ are non-negative coefficients.

The type of friction in this system makes qualitative analysis a complex task.

Building on the works of (Leonov et al., 2012; Bragin et al., 2011; Leonov and Kuznetsov, 2011b,a; Kuznetsov et al., 2011; Leonov et al., 2010; Bragin et al., 2010; Leonov et al., 2010b), some aspects of the numerical modeling of oscillations of continuous dynamical systems will be described, which are of crucial importance to engineers for practical applications. Computer modeling of the system was carried out. Once again, the computer modeling for this system requires a special method for discontinuous right-hand systems (see Appendix 3). Frictional oscillations are of particular interest in this scenario. Several studies have been devoted to these frictional oscillations (Hensen, 2002; Hensen and van de Molengraft, 2002; Juloski et al., 2005; Mallon, 2003; Mallon et al., 2006; Olsson, 


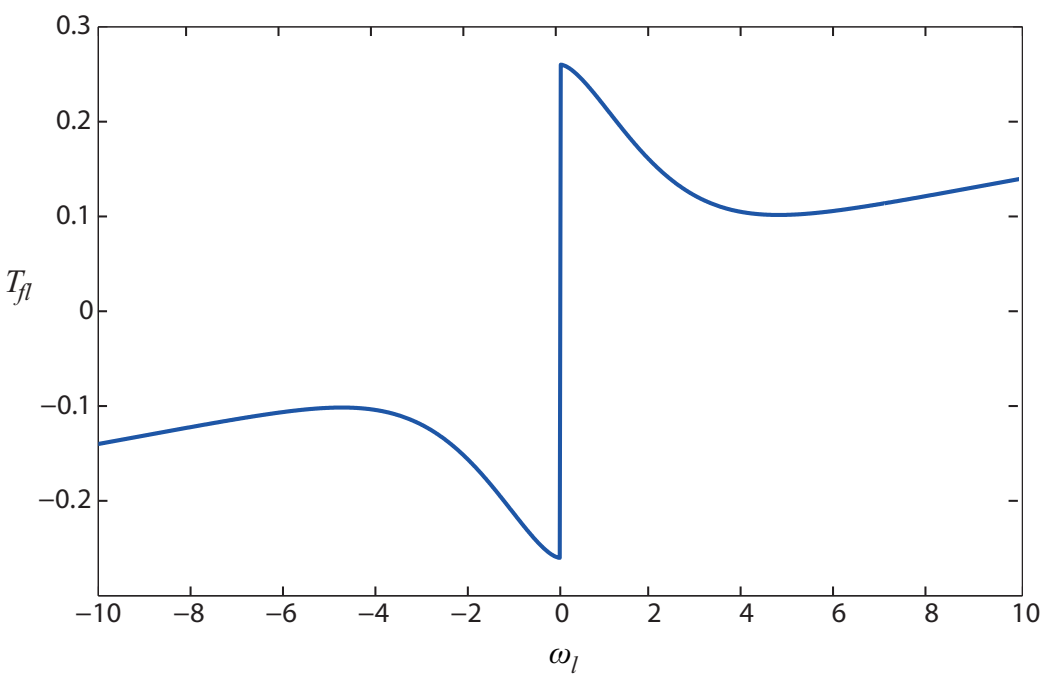

FIGURE 8 Friction torque $T_{f l}$

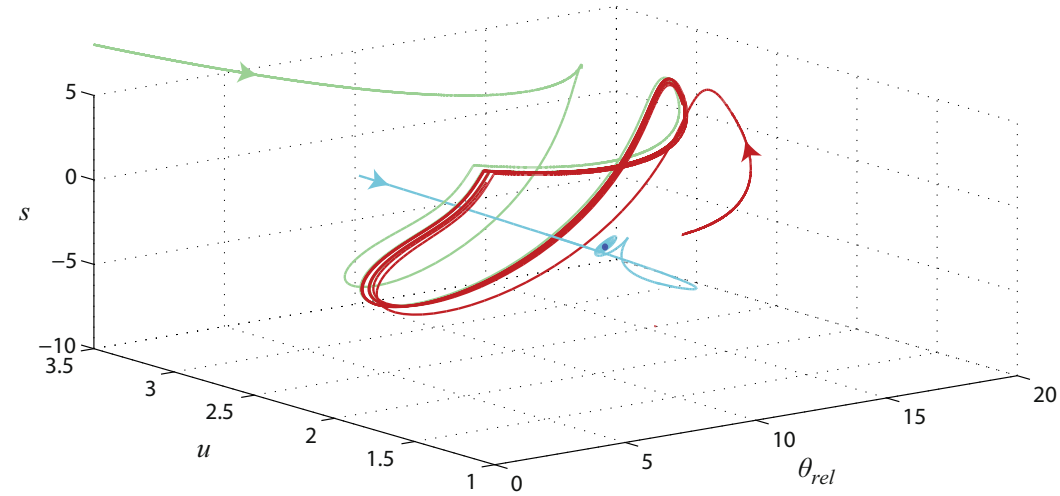

FIGURE 9 Hidden oscillations in space $\left(\theta_{\text {rel }}, s, u\right)$

1996; Olsson and Astrom, 1996, 2001; Putra, 2004; Putra et al., 2004; Putra and Nijmeijer, 2003, 2004; van de Wouw et al., 2005; Al-Bender et al., 2004; Batista and Carlson, 1998), as wear and damage to various mechanical systems are often caused by these oscillations. Under certain parameters, the so called hidden oscillations (Leonov et al., 2011d; Bragin et al., 2011; Leonov et al., 2012; Leonov and Kuznetsov, 2013b) may emerge - oscillations in which the basin of attraction does not intersect with small neighborhoods of equilibrium states.

Numerical simulation of complex nonlinear dynamical systems is now possible thanks to the development of computer modeling technology. This allows for new information about the behavior of the trajectory of these systems. In the well-known Duffing system (Duffing, 1918), Van der Pol system (van der Pol, 


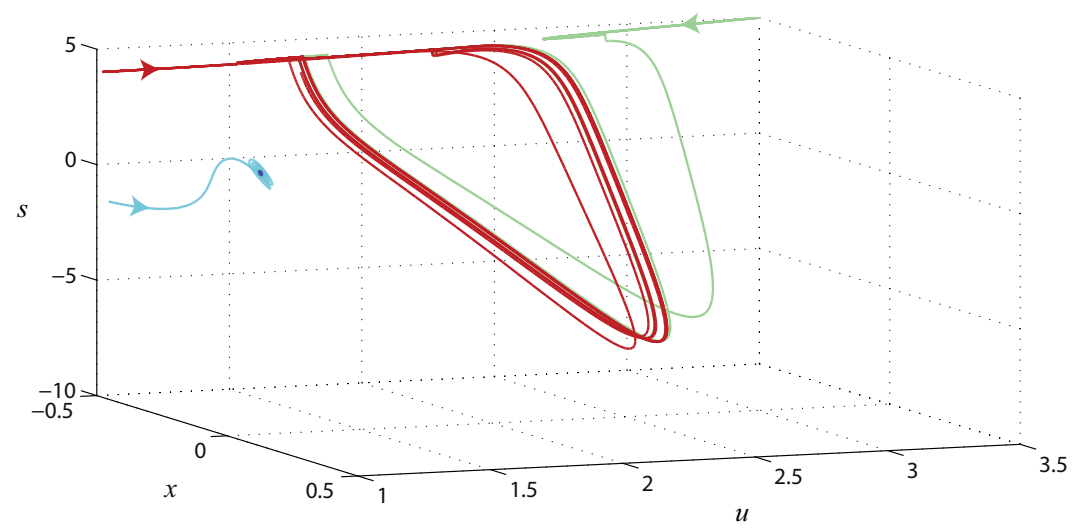

FIGURE 10 Hidden oscillations in space $\{x, s, u\}$

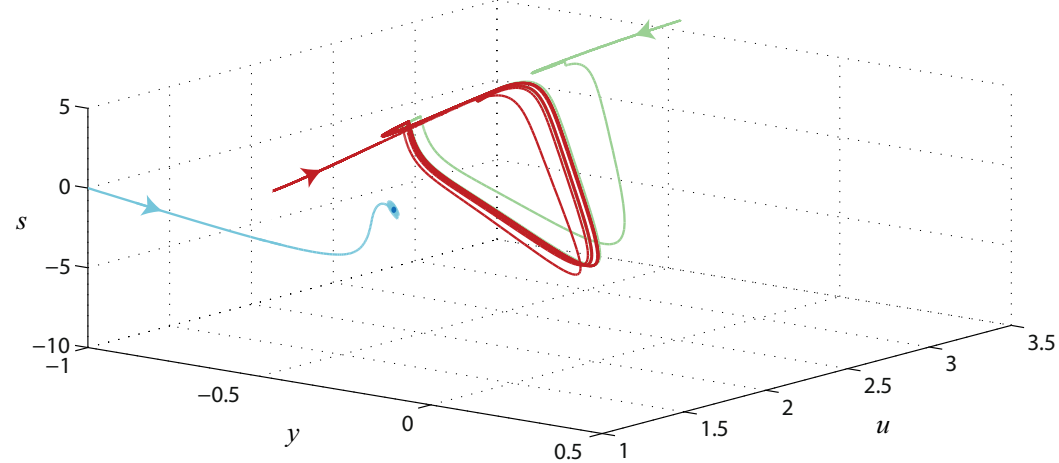

FIGURE 11 Hidden oscillations in space $\{y, s, u\}$

1927) Belousov-Zhabotinsky system (Belousov, 1959), Lorenz system (Lorenz, 1963), Roessler system (Rössler, 1976) and other systems, classic self-exciting oscillations and the attractors can be obtained numerically by using the standard computational procedure: a trajectory beginning in an unstable equilibrium state reaches an oscillation and defines it after the transient process. s This approach has limited applications, however. In the middle of the last century, another sort of oscillation was obtained in systems with scalar nonlinearity. These "hidden oscillations" cannot be calculated with the previous method described above. In such cases, the simulation of trajectories with random initial data is unlikely to give the desired result (e.g., the description of the experiment by Kolmogorov related to the search of limit cycles (Arnol'd, 2005; Leonov and Kuznetsov, 2007; Leonov et al., 2011a; Kuznetsov, 2008; Leonov et al., 2008; Kuznetsov and Leonov, 2008; Leonov, 2010; Leonov and Kuznetsov, 2010; Bragin et al., 2011; Kuznetsov et al., 2013)), as the domain of attraction can be very small and the dimension of the attractor can be significantly smaller than the dimension of the system. 
In 1961, Gubar (Gubar', 1961; Leonov and Kuznetsov, 2013b) demonstrated the possible existence of hidden oscillations analytically in a two-dimensional phase locked loop with piecewise constant pulse nonlinearity. In the 1950's and 60's, research into hypotheses (Aizerman, 1949; Kalman, 1957; Markus and Yamabe, 1960) regarding absolute stability led to the discovery of hidden oscillations in automatic control systems with piecewise-linear non-linearity. These oscillations were found to be present in the linear stability region (see (Pliss, 1958; Bernat and Llibre, 1996; Leonov et al., 2010a; Leonov and Kuznetsov, 2013b; Bragin et al., 2011), etc.).

In studies by (Kuznetsov et al., 2010, 2011; Leonov et al., 2011b; Bragin et al., 2011; Leonov et al., 2011d; Kuznetsov et al., 2011; Leonov et al., 2011c; Vagaitsev, 2012; Leonov et al., 2012; Leonov and Kuznetsov, 2012; Kuznetsov et al., 2013; Leonov and Kuznetsov, 2013b,c,a, 2014), chaotic hidden oscillations, acting as hidden attractors, were discovered in the Chua circuit.

In the double-mass model of the induction motor-actuated drilling system described in PII-PV, hidden oscillations were found.

The stable equilibrium states and stable limit cycles are depicted in Fig. 911 (see PIII). In accordance with the previous statement, this implies that hidden frictional oscillations are present in the system, which suggests that complex phenomena such as hidden oscillations may appear even in comparatively simple models. The detection of hidden oscillations is a difficult task; given the small region of attraction, the probability of finding these oscillations while modeling a system with random data is very low. New approaches are needed in order to properly study and understand these systems. Note that in the case presented in this study, these are stick-slip type hidden oscillations - they pass through the sliding region created by the sudden discontinuity. Thus, the modelling should take place in the region of discontinuity in order to observe the phenomenon. 


\section{CONCLUSION}

This dissertation is devoted to a topic particularly important for the oil and gas industry - study of the drilling systems. As shown in the first chapter, drilling systems experience time- and cost-consuming failures, so it is necessary to look for new ways of failures reduction.

In the second chapter two new mathematical models of the drilling systems are developed and studied. It is shown how different types of loads may affect the operation of the drilling system. The obtained results also give a better understanding of the reasons of drill-string failures. Thus, hidden oscillations found in the second model show that such a standard approach of the engineers when the study of the drilling system is mainly based on local analysis of equilibria is not efficient.

This work has potential for future investigations. First of all, more complex mathematical models based on the models developed in the current research can be obtained by lessening some limitations. Second of all, the numerical results are obtained with the help of Matlab. It would be interesting to try out the same modelling in some other mathematical packages as well. For example, in Maple with more accuracy settings. Another variant of future investigations could be the development of analytical methods for finding hidden oscillations. Also a state-feedback control could be created for the second mathematical model of the drilling system in order to stabilise the equilibrium, as it was done in (De Bruin et al., 2009) for the model which motivated this research. 


\section{YHTEENVETO (FINNISH SUMMARY)}

Tämä työ käsittelee oikosulkumoottoriin perustuvien porausjärjestelmien sähkömekaanisia malleja. Aihe on ajankohtainen, koska porauslaitteiston vahingoittuminen aiheuttaa huomattavia aikataulullisia menetyksiä ja taloudellisia kustannuksia öljy- ja kaasualalla toimiville yrityksille. Vaikka näistä järjestelmistä on tehty merkittävä määrä tutkimuksia, porauslaitevikoja esiintyy edelleen usein öljy- ja kaasuteollisuudessa.

Tässä työssä tutkitaan porauslaitteiston sähkömekaanisia malleja, jotka toimivat oikosulkumoottoreilla. Työ pohjautuu Eindhovenin Teknillisen Yliopiston tutkijoiden tutkimuksiin, jotka kehittivät porausjärjestelmän koemallin. Tämä malli koostuu kahdesta levystä, jotka ovat yhdistetty toisiinsa terästangolla ja johon kohdistuu vääntörasituksia. Ylempi levy on yhdistetty käyttölaitteeseen. Alempaan levyyn, joka toimii poran varren päänä, vaikuttaa kitkavoima, joka johtuu pääasiassa kivilajien vuorovaikutuksesta. Keskeinen ajatus, joka erottaa tämän tutkimuksen aiempaa mallia koskevasta tutkimuksesta, on monimutkaisempien käyttölaitteeseen liittyvien yhtälöiden käyttäminen, erityisesti oikosulkumoottoriin liittyen.

Tässä työssä on otettu huomioon kaksi uutta matemaattista mallia. Ensimmäinen malli on yksinkertaistettu, tavallisen porakoneen prototyyppi. Tässä tapauksessa oletetaan, että pora on täysin jäykkä, ja että kitkavoima on epäsymmetristä Coulombin tyyppiä. Analyysimallin laadullisen tutkimuksen avulla selvitettiin sallitun kuormituksen arvot (niin sanotun kitkavoimamomentin sallitut arvot), joilla järjestelmä pysyi toiminnassa huolimatta porausympäristön muutoksesta. Tietokonemallinnusta käyttämällä analysoitiin myös äkillinen kuorman kasvu.

Toinen matemaattinen malli ottaa huomioon poran vääntömuodon muutokset porauksen aikana. Kitkamomentista, joka aiheuttaa epäsymmetrisen Cou-lombin tyyppisen reaktion, tehtiin järjestelmän paikallinen analyysi. Tutkimuksen tekijä teki tietokonemallinnuksen Eindhovenin yliopiston tutkijoiden luoman kitkamallin pohjalta. Tässä mallissa havaittiin mielenkiintoinen vaikutus, joka johtui piilevästä slip-stick -liikkeestä.

Tämän tutkimuksen tulokset on julkaistu 11 artikkelissa. 


\section{REFERENCES}

Adkins, B. 1957. The General Theory of Electrical Machines. John Wiley and Sons Inc.

Aizerman, M. A. 1949. The problem of the stability in the "large" of dynamical systems. Russian Mathematical Surveys 4 (4), 187-188.

Al-Bender, F., Lampaert, V. \& Swevers, J. 2004. Modeling of dry sliding friction dynamics: From heuristic models to physically motivated models and back. Chaos: An Interdisciplinary Journal of Nonlinear Science 14 (2), 446-460.

Andronov, A. \& Mayer, A. 1947. The vyshnegradsky problem in the theory of direct regulation. Avtomatika i Telemekhanika 8 (5), 314-334 [in Russian].

Andronov, A., Vitt, A. \& Haikin, S. 1981. Theory of oscillations. Nauka, Glavnaya redaktsiya fiziko-matematicheskoy literaturi [in Russian].

Andronov, A. A., Vitt, A. A. \& Khaikin, S. E. 1966. Theory of oscillations. Fizmatgiz, Moscow, 1959; English transl. Pergamon Press, Oxford, and AddisonWesley, Reading, Mass.

Arnol'd, V. 2005. Experimental Mathematics. Moscow[in Russian]: Fazis.

Ashino, R., Nagase, M. \& Vaillancourt, R. 2000. Behind and beyond the MATLAB ODE suite. Computers \& Mathematics with Applications 40 (4), 491-512.

Barbashin, E. \& Krasovsky, N. 1952. Stability of oscillations in general. Doklady Akademii Nauk USSR 86 (3), 453-456 [in Russian].

Barbashin, E. 1967. Introduction to stability theory. Nauka, Glavnaya redaktsiya fiziko-matematicheskoy literaturi [in Russian].

Batista, A. \& Carlson, J. 1998. Bifurcations from steady sliding to stick slip in boundary lubrication. Physical Review E 57 (5), 4986-4996.

Belousov, B. 1959. Collection of short papers on radiation medicine. Medgiz, Moskow.

Bernat, J. \& Llibre, J. 1996. Counterexample to Kalman and Markus-Yamabe conjectures in dimension larger than 3. Dynamics of Continuous, Discrete and Impulsive Systems 2 (3), 337-279.

Bespalov, V., Moshinsky, Y. \& Petrov, A. 2002. Mathematical model of an induction motor in generalized orthogonal coordinate system. Electrichestvo 8, 33-39 [in Russian].

Bespalov, V. 1992. Induction motors for dynamical operation modes. Moscow Power Engineering Institute [in Russian]. 
Besselink, B., Van De Wouw, N. \& Nijmeijer, H. 2011. A semi-analytical study of stick-slip oscillations in drilling systems. Journal of Computational and Nonlinear Dynamics 6 (2).

Bothe, D. 1999. Periodic solutions of non-smooth friction oscillators. Zeitschrift für angewandte Mathematik und Physik ZAMP 50 (5), 779-808.

Bragin, V. O., Kuznetsov, N. V. \& Leonov, G. A. 2010. Algorithm for counterexamples construction for Aizerman's and Kalman's conjectures. IFAC Proceedings Volumes (IFAC-PapersOnline) 4 (1), 24-28. doi:10.3182/20100826-3-TR-4016. 00008.

Bragin, V. O., Vagaitsev, V. I., Kuznetsov, N. V. \& Leonov, G. A. 2011. Algorithms for finding hidden oscillations in nonlinear systems. The Aizerman and Kalman conjectures and Chua's circuits. Journal of Computer and Systems Sciences International 50 (4), 511-543. doi:10.1134/S106423071104006X.

Brett, J. F. 1992. The genesis of torsional drillstring vibrations. SPE Drilling Engineering 7 (3), 168-174.

De Bruin, J. C. A., Doris, A., van de Wouw, N., Heemels, W. P. M. H. \& Nijmeijer, H. 2009. Control of mechanical motion systems with non-collocation of actuation and friction: A Popov criterion approach for input-to-state stability and set-valued nonlinearities. Automatica 45 (2), 405-415.

Drury, B. 2001. Control Techniques Drives and Controls Handbook. The Institution of Electrical Engineers.

Duffing, G. 1918. Erzwungene Schwingungen bei Veranderlicher Eigenfrequenz. Braunschweig: Friedrich Vieweg \& Sohn Verlag.

Fečkan, M. 1997. Bifurcation of periodic solutions in differential inclusions. Applications of Mathematics 42 (5), 369-393.

Fečkan, M. 1999. Chaotic solutions in differential inclusions: chaos in dry friction problems. Transactions of the American Mathematical Society 351 (7), 28612873.

Filippov, A. 1960. Differential equations with discontinuous righthand side. Matematichesky Sbornik 51 (1), 99-128 [in Russian].

Filippov, A. 1985. Differential Equations with Discontinuous Righthand Side. Moscow [in Russian]: Nauka.

Filippov, A. 1988. Differential Equations with Discontinuous Righthand Sides, Vol. 18. Springer. Mathematics and its Applications.

Gelig, A., Leonov, G. \& Yakubovish, V. 1978. Stability of nonlinear systems with non-unique equilibrium state. Nauka [in Russian]. 
Germay, C., Van de Wouw, N., Nijmeijer, H. \& Sepulchre, R. 2009. Nonlinear drillstring dynamics analysis. SIAM Journal on Applied Dynamical Systems 8 (2), 527-553.

Germay, C. 2002. Self-Excited Oscillations of Drag Bits. Master Thesis. The University of Minnesota, The Faculty of the Graduate School.

Golubev, A. \& Zikov, B. 2003. Mathematical model of an induction motor with multi-phase windings of stator and rotor. Electrotehnika 7, 35-40 [in Russian].

Gruzov, L. 1953. Methods of mathematical investigation of electrical machines. Gosenergoizdat M.- L. [in Russian].

Gubar', N. 1961. Investigation of a piecewise linear dynamical system with three parameters. Journal of Applied Mathematics and Mechanics 25, 1519-1535.

Hall, D. R. \& Shumway, J. 2009. System for steering a drill string. US Patent $7,600,586$.

Hensen, R. \& van de Molengraft, M. 2002. Friction induced hunting limit cycles: an event mapping approach. In American Control Conference, 2002. Proceedings of the 2002, Vol. 3. IEEE, 2267-2272.

Hensen, R. 2002. Controlled mechanical systems with friction. Technische Universiteit Eindhoven.

Higham, D. J. \& Higham, N. J. 2005. MATLAB guide. Philadelphia: SIAM.

Hild, F. W. 1934. Earth drilling system. US Patent 1,962,346.

Horbeek, J. H., Birch, W., McMahon, M. J. \& Fearnley, K. 1995. Successful reduction of north sea drillstring failures. In Successful reduction of North Sea drillstring failures. Society of Petroleum Engineers, 43-51.

Hrisanov, V. \& Brxhezinsky, R. 2003. Adequacy questions of mathematical models of an asynchronous motor in context of analysis of the launch transient processes. Electrotechnica 10, 20-25 [in Russian].

Hurwitz, A. 1964. On the conditions under which an equation has only roots with negative real parts. Selected Papers on Mathematical Trends in Control Theory (R. Bellman and R. Kalaba, eds.), Vol. 65.

Jansen, J. D. \& Van den Steen, L. 1995. Active damping of self-excited torsional vibrations in oil well drillstrings. Journal of Sound and Vibration 179 (4), 647668.

Jansen, J. D. 1991. Non-linear rotor dynamics as applied to oilwell drillstring vibrations. Journal of Sound and Vibration 147 (1), 115-135. 
Juloski, A. L., Mihajlović, N., Heemels, W. P. M. H., Van de Wouw, N. \& Nijmeijer, H. 2005. Friction induced hunting limit cycles: an event mapping approach. In Proceeding of the 44th IEEE Conference on Decision and Control, Seville, Spain. IEEE.

Kalman, R. E. 1957. Physical and mathematical mechanisms of instability in nonlinear automatic control systems. Transactions of ASME 79 (3), 553-566.

Keuzer, E. \& Kust, O. 1997. Controlling torsional vibrations through proper orthogonal decomposition. In IUTAM Symposium on Interaction between Dynamics and Control in Advanced Mechanical Systems. Springer, 207-214.

Khalil, H. K. \& Grizzle, J. W. 2002. Nonlinear systems (3rd edition). Upper Saddle River: Prentice Hall.

Kiseleva, M. 2013. Oscillations and Stability of Drilling Systems: Analytical and Numerical Methods, Vol. 3. St. Petersburg University Press.

Kiseleva, M. A., Leonov, G. \& Neittaanmäki, P. 2010. Mathematical problem for drilling system. In Proceedings of International Workshop "Mathematical and Numerical Modeling in Science and Technology", 16-19.

Kiseleva, M. A. \& Leonov, G. 2012. Stability problem of the drilling system under the abruptly variable load. In Proceedings of International Scientific Conference on Mechanics "Sixth Polyahov Readings", Saint Petersburg, Russia, p. 45.

Kiseleva, M. A. 2011. Development and realization of the algorithm of stability boundaries types analysis. In Proceedings of SPISOK-2011, Saint Petersburg, Russia, p. 387.

Kiseleva, M. A. 2012a. Local stability of drilling systems with asynchronous motor. Vestnik Saint Petersburg State University 1 (3), 39-41.

Kiseleva, M. A. 2012b. Mathematical model of a drilling system actuated by an induction motor. In Proceedings of XII International conference Stability and oscillations of nonlinear control systems, Moscow, Russia, p. 171.

Kiseleva, M. A. 2013. Oscillations of dynamical systems applied in drilling. In Proceedings of the International Conference of Young Scientists AUTOMATION \& Control, Saint Petersburg, Russia, p. 225.

Kopilov, I., Morozkin, V. \& Klokov, B. 2002. Engineering of electrical machines. Moscow [in Russian]: Visshaya shkola.

Kopilov, I. 2001a. Mathematical modeling of electrical machines. Moscow [in Russian]: Visshaya shkola.

Kopilov, I. 2001b. Mathematical modeling of electrical machines: college textbook. Moscow [in Russian]: Visshaya shkola. 
Kreuzer, E. \& Kust, O. 1996a. Analyse selbsterregter drehschwingungen in torsionsstäben. ZAMM-Journal of Applied Mathematics and Mechanics/Zeitschrift für Angewandte Mathematik und Mechanik 76 (10), 547-557.

Kreuzer, E. \& Kust, O. 1996b. Analysis of long torsional strings by proper orthogonal decomposition. Archive of Applied Mechanics 67 (1-2), 68-80.

Krishenko, A. P. 2007. Stability of motion of autonomous systems. Moscow [in Russian]: Bauman Moscow State Technical University.

Kunze, M. \& Küpper, T. 1997. Qualitative bifurcation analysis of a non-smooth friction-oscillator model. Zeitschrift für Angewandte Mathematik und Physik (ZAMP) 48 (1), 87-101.

Kunze, M. 2000. Non-smooth dynamical systems, Vol. 1744. Springer Verlag.

Kust, O. 1998. Selbsterregte drehschwingungen in schlanken torsionssträngen. Nichtlineare Dynamik und Regelung, Dissertation, VDI Verlag, Reihe 11.

Kuznetsov, N., Kuznetsova, O., Leonov, G. \& Vagaitsev, V. 2013. Analyticalnumerical localization of hidden attractor in electrical Chua's circuit. Springer. Informatics in Control, Automation and Robotics, Lecture Notes in Electrical Engineering, Vol. 174, Part 4, 149-158. doi:10.1007/978-3-642-31353-0_11.

Kuznetsov, N. V., Kuznetsova, O. A., Leonov, G. A. \& Vagaytsev, V. I. 2011. Hidden attractor in Chua's circuits. ICINCO 2011 - Proceedings of the 8th International Conference on Informatics in Control, Automation and Robotics 1, 279283. doi:10.5220/0003530702790283.

Kuznetsov, N. V., Kuznetsova, O. A. \& Leonov, G. A. 2013. Visualization of four normal size limit cycles in two-dimensional polynomial quadratic system. Differential equations and dynamical systems 21 (1-2), 29-34. doi:10.1007/ s12591-012-0118-6.

Kuznetsov, N. V., Leonov, G. A. \& Seledzhi, S. M. 2011. Hidden oscillations in nonlinear control systems. IFAC Proceedings Volumes (IFAC-PapersOnline) 18 (1), 2506-2510. doi:10.3182/20110828-6-IT-1002.03316.

Kuznetsov, N. V., Leonov, G. A. \& Vagaitsev, V. I. 2010. Analyticalnumerical method for attractor localization of generalized Chua's system. IFAC Proceedings Volumes (IFAC-PapersOnline) 4 (1), 29-33. doi:10.3182/ 20100826-3-TR-4016.00009.

Kuznetsov, N. V. \& Leonov, G. A. 2008. Lyapunov quantities, limit cycles and strange behavior of trajectories in two-dimensional quadratic systems. Journal of Vibroengineering 10 (4), 460-467.

Kuznetsov, N. V., Vagaytsev, V. I., Leonov, G. A. \& Seledzhi, S. M. 2011. Localization of hidden attractors in smooth Chua's systems. In International Conference on Applied and Computational Mathematics, 26-33. 
Kuznetsov, N. V. 2008. Stability and Oscillations of Dynamical Systems: Theory and Applications. Jyväskylä University Printing House.

Kuznetsov, Y. A., Rinaldi, S. \& Gragnani, A. 2003. One-parameter bifurcations in planar Filippov systems. International Journal of Bifurcation and chaos 13 (08), 2157-2188.

Kyllingstad, A. \& Halsey, G. W. 1988. A study of slip/stick motion of the bit. SPE Drilling Engineering 3 (4), 369-373.

LaSalle, J. P. 1968. Stability theory for ordinary differential equations. Journal of Differential Equations 4, 57-65.

Leine, R. I. 2000. Bifurcations in discontinuous mechanical systems of the Fillippov-type. Technische Universiteit Eindhoven.

Leine, R. \& Van Campen, D. 2005. Stick-slip whirl interaction in drillstring dynamics. In IUTAM Symposium on Chaotic Dynamics and Control of Systems and Processes in Mechanics. Springer, 287-296.

Leonhard, W. 2001. Control of electrical drives. Springer.

Leonov, G. \& Kondrat'eva, N. 2009. Stability analisys of AC electrical machines. Unipress [in Russian].

Leonov, G. 2010. Efficient methods in the search for periodic oscillations in dynamical systems. Journal of Applied Mathematics and Mechanics 74 (1), 24-50.

Leonov, G. A., Bragin, V. O. \& Kuznetsov, N. V. 2010a. Algorithm for constructing counterexamples to the Kalman problem. Doklady Mathematics 82 (1), 540542. doi:10.1134/S1064562410040101.

Leonov, G. A., Bragin, V. O. \& Kuznetsov, N. V. 2010b. On problems of Aizerman and Kalman. Vestnik St. Petersburg University. Mathematics 43 (3), 148-162. doi:10.3103/S1063454110030052.

Leonov, G. A., Kuznetsov, N. V., Kiseleva, M. A., Solovyeva, E. P. \& Zaretskiy, A. M. 2014. Hidden oscillations in mathematical model of drilling system actuated by induction motor with a wound rotor [submitted]. Nonlinear Dynamics.

Leonov, G. A., Kuznetsov, N. V. \& Kudryashova, E. V. 2008. Cycles of two-dimensional systems: Computer calculations, proofs, and experiments. Vestnik St.Petersburg University. Mathematics 41 (3), 216-250. doi:10.3103/ S1063454108030047.

Leonov, G. A., Kuznetsov, N. V. \& Kudryashova, E. V. 2011a. A direct method for calculating Lyapunov quantities of two-dimensional dynamical systems. Proceedings of the Steklov Institute of Mathematics 272 (Suppl. 1), S119-S127. doi:10.1134/S008154381102009X. 
Leonov, G. A., Kuznetsov, N. V., Kuznetsova, O. A., Seledzhi, S. M. \& Vagaitsev, V. I. 2011b. Hidden oscillations in dynamical systems. Transaction on Systems and Control 6 (2), 54-67.

Leonov, G. A., Kuznetsov, N. V. \& Seledzhi, S. M. 2011c. Hidden oscillations in dynamical systems. In Recent researches in System Science. Proceedings of the 15th WSEAS International Conference on Systems (Part of the 15th WSEAS CSCC Multiconference). WSEAS, 292-297.

Leonov, G. A., Kuznetsov, N. V. \& Vagaitsev, V. I. 2011d. Localization of hidden Chua's attractors. Physics Letters A 375 (23), 2230-2233. doi:10.1016/j.physleta. 2011.04.037.

Leonov, G. A., Kuznetsov, N. V. \& Vagaitsev, V. I. 2012. Hidden attractor in smooth Chua systems. Physica D: Nonlinear Phenomena 241 (18), 1482-1486.

Leonov, G. A. \& Kuznetsov, N. V. 2007. Computation of the first Lyapunov quantity for the second-order dynamical system. IFAC Proceedings Volumes (IFACPapersOnline) 3, 87-89. doi:10.3182/20070829-3-RU-4912.00014.

Leonov, G. A. \& Kuznetsov, N. V. 2010. Limit cycles of quadratic systems with a perturbed weak focus of order 3 and a saddle equilibrium at infinity. Doklady Mathematics 82 (2), 693-696. doi:10.1134/S1064562410050042.

Leonov, G. A. \& Kuznetsov, N. V. 2011a. Analytical-numerical methods for investigation of hidden oscillations in nonlinear control systems. IFAC Proceedings Volumes (IFAC-PapersOnline) 18 (1), 2494-2505.

Leonov, G. A. \& Kuznetsov, N. V. 2011b. Algorithms for searching for hidden oscillations in the Aizerman and Kalman problems. Doklady Mathematics 84 (1), 475-481. doi:10.1134/S1064562411040120.

Leonov, G. A. \& Kuznetsov, N. V. 2012. IWCFTA2012 Keynote speech I - Hidden attractors in dynamical systems: From hidden oscillation in HilbertKolmogorov, Aizerman and Kalman problems to hidden chaotic attractor in Chua circuits. In Chaos-Fractals Theories and Applications (IWCFTA), 2012 Fifth International Workshop on, XV-XVII. doi:10.1109/IWCFTA.2012.8.

Leonov, G. A. \& Kuznetsov, N. V. 2013a. Analytical-numerical methods for hidden attractors' localization: the 16th Hilbert problem, Aizerman and Kalman conjectures, and Chua circuits. Springer. Numerical Methods for Differential Equations, Optimization, and Technological Problems, Computational Methods in Applied Sciences, Vol. 27, Part 1, 41-64. doi:10.1007/978-94-007-5288-7_ 3.

Leonov, G. A. \& Kuznetsov, N. V. 2013b. Hidden attractors in dynamical systems. From hidden oscillations in Hilbert-Kolmogorov, Aizerman, and Kalman problems to hidden chaotic attractors in Chua circuits. International Journal of Bifurcation and Chaos 23 (1). doi:10.1142/S0218127413300024. (art. no. 1330002). 
Leonov, G. A. \& Kuznetsov, N. V. 2013c. Prediction of hidden oscillations existence in nonlinear dynamical systems: analytics and simulation, Vol. 210 AISC. Springer. Advances in Intelligent Systems and Computing, 5-13. doi: 10.1007/978-3-319-00542-3_3.

Leonov, G. A. \& Kuznetsov, N. V. 2014. Nonlinear Mathematical Models Of PhaseLocked Loops. Stability and Oscillations, Vol. 7. Cambridge Scientific Press.

Leonov, G. A., Solovyeva, E. P. \& Zaretskiy, A. M. 2013. An estimation method of transient processes of induction machines. Vestnik St. Petersburg University 46 (3), 150-168.

Leonov, G. A. \& Solovyeva, E. P. 2012. On a special type of stability of differential equations for induction machines with double squirrel-cage rotor. Vestnik St. Petersburg University. Mathematics 45 (3), 128-135.

Leonov, G. A., Vagaitsev, V. I. \& Kuznetsov, N. V. 2010. Algorithm for localizing Chua attractors based on the harmonic linearization method. Doklady Mathematics 82 (1), 663-666. doi:10.1134/S1064562410040411.

Leonov, G. A. 2001. Mathematical Problems of Control Theory: An Introduction. World Scientific Publishing Company.

Leonov, G. A. 2006. Phase synchronization: Theory and application. Automation and Remote Control 10, 1573-1609.

Lorenz, E. 1963. Deterministic nonperiodic flow. Journal of the Atmospheric Sciences 20 (2), 130-141.

Lyapunov, A. M. 1950. The general problem of the stability of motion. Gostechizdat, Moscow [in Russian].

Mallon, N., van de Wouw, N., Putra, D. \& Nijmeijer, H. 2006. Friction compensation in a controlled one-link robot using a reduced-order observer. Control Systems Technology, IEEE Transactions on 14 (2), 374-383.

Mallon, N. 2003. Reduced-Order Observer Based Friction Compensation for a Controlled One-Link Robot. Eindhoven University of Technology, Department of Mechanical Engineering.

Marchaud, A. 1936. Sur les champs continus de demi-cônes convexes et leurs intégrales. Compositio Mathematica 3, 89-127.

Markus, L. \& Yamabe, H. 1960. Global stability criteria for differential systems. Osaka Journal of Mathematics 12 (2), 305-317.

Mihajlović, N., Van Veggel, A. A., Van de Wouw, N., Nijmeijer, H. \& Den Dolech, P. O. 2004a. Friction-induced torsional vibrations in an experimental drill-string system. In Proceedings of the 23rd IASTED International Conference. 
Mihajlović, N., Van de Wouw, N., Hendriks, M. P. M. \& Nijmeijer, H. 2004b. Analysis of friction-induced limit cycling in an experimental drill-string setup. ASME Journal of Dynamic Systems, Measurements and Control 126 (4), 709-720.

Mihajlović, N., Van de Wouw, N., Hendriks, M. P. M. \& Nijmeijer, H. 2005. Friction-induced vibrations in an experimental drill-string system for various friction situations. In Proceedings of the ENOC-2005.

Mihajlović, N., Van de Wouw, N., Hendriks, M. P. M. \& Nijmeijer, H. 2006. Friction-induced limit cycling in flexible rotor systems: An experimental drillstring set-up. Nonlinear Dynamics 46 (3), 273-291.

Mihajlović, N., Van de Wouw, N., Rosielle, P. C. J. N. \& Nijmeijer, H. 2007. Interaction between torsional and lateral vibrations in flexible rotor systems with discontinuous friction. Nonlinear Dynamics 50 (3), 679-699.

Mihajlović, N. 2005. Torsional and lateral vibrations in flexible rotor systems with friction. Technische Universiteit Eindhoven.

Moshinsky, Y. A. \& Petrov, A. P. 2001. Mathematical model of an induction capasitor-start motor according to the method of symmetrical components with the help of standart software. Elektrichestvo, 40-43 [in Russian].

Moshinsky, Y. A. \& Petrov, A. P. 2007. Mathematical model for investigation of induction motor in the context of stopway. Elektrotehnika 1, 19-22 [in Russian].

Moshinsky, Y. A. \& T., A. V. 2007. Generalized mathematical model of frequency regulated induction motor taking into account steel losses. Elektrichestvo 11, 60-66 [in Russian].

Neimark, Y. I. 1972. Method of point mapping in the theory of nonlinear oscillations. Nauka [in Russian].

Olsson, H. \& Astrom, K. 1996. Friction generated limit cycles. In Control Applications, 1996., Proceedings of the 1996 IEEE International Conference on. IEEE, 798-803.

Olsson, H. \& Astrom, K. 2001. Friction generated limit cycles. Control Systems Technology, IEEE Transactions on 9 (4), 629-636.

Olsson, H. 1996. Control systems with friction. Department of Automatic Control, Lund Institute of Technology.

Omojuwa, E., Osisanya, S. \& Ahmed, R. 2011. Measuring and controlling torsional vibrations and stick-slip in a viscous-damped drillstring model. In International Petroleum Technology Conference, Bangkok, Thailand.

Pankratov, V. \& Zima, E. 2003. Mathematical modeling og induction electrical machines and double-powered machines. Elektrotehnika 9, 19-25 [in Russian]. 
Piiroinen, P. 2007. Filippov system solver for Matlab. Department of Mathematical Physics, National University of Ireland, Galway, Galway, Ireland, www.maths-physics.nuigalway.ie/users/Piiroinen/Filippov/.

Piiroinen, P. T. \& Kuznetsov, Y. A. 2008. An event-driven method to simulate Filippov systems with accurate computing of sliding motions. ACM Transactions on Mathematical Software (TOMS) 34 (3), 1-24.

Pliss, V. A. 1958. Some Problems in the Theory of the Stability of Motion. Leningrad [in Russian]: Izd. LGU.

van der Pol, B. 1927. On relaxation-oscillations. Philosophical Magazine and Journal of Science 2 (7), 978-992.

Popescu, M. 2000. Induction motor modelling for vector control purposes, 144 .

Putra, D., Moreau, L. \& Nijmeijer, H. 2004. Observer-based compensation of discontinuous friction. In Decision and Control, 2004. CDC. 43rd IEEE Conference on, Vol. 5. IEEE, 4940-4945.

Putra, D. \& Nijmeijer, H. 2003. Limit cycling in observer-based controlled mechanical systems with friction. In Proceedings of the 2003 European Control Conference (to appear). Cambridge.

Putra, D. \& Nijmeijer, H. 2004. Limit cycling in an observer-based controlled system with friction: Numerical analysis and experimental validation. International Journal of Bifurcation and Chaos 14 (09), 3083-3093.

Putra, D. 2004. Control of limit cycling in frictional mechanical systems. Technische Universiteit Eindhoven.

Rössler, O. 1976. An equation for continuous chaos. Physics Letters 57A (5), 397398.

Rajnauth, J. 2003. Reduce torsional vibration and improve drilling operations. In SPE Latin American and Caribbean Petroleum Engineering Conference.

Richard, T., Germay, C. \& Detournay, E. 2004. Self-excited stick-slip oscillations of drill bits. Comptes rendus MECANIQUE 332 (8), 619-626.

Routh, E. J. 1877. A treatise on the stability of a given state of motion: particularly steady motion. Macmillan and co.

Shampine, L. F. \& Reichelt, M. W. 1997. The MATLAB ODE suite. SIAM journal on scientific computing 18 (1), 1-22.

Shokir, E. M. 2004. A novel PC program for drill string failure detection and prevention before and while drilling specially in new areas. Oil and gas business, Vol. 1. 
Sipaylov, G. \& Loos, A. 1980. Mathematical model of electrical machines (AVM): Textbook for college students. Moscow [in Russian]: Visshaya shkola.

Skubov, D. \& Khodzhaev, K. S. 2008. Non-Linear Electromechanics. Springer.

Solovyeva, E. 2011. Mathematical models and stability analysis of induction motors. Master Thesis. University of Jyväskylä.

Staege, S. A. 1936. Electrical differential oil well. Westinghouse Electric \& Manufacturing Company. (US Patent 2,032,155).

Van den Steen, L. 1997. Suppressing Stick-Slip-Induced Drill-string Oscillations: a Hyper Stability Approach. University of Twente.

Tucker, W. R. \& Wang, C. 1999. An integrated model for drill-string dynamics. Journal of Sound and Vibration 224 (1), 123-165.

Utkin, V. I. 1992. Sliding modes in control and optimization, Vol. 116. SpringerVerlag Berlin.

Vagaitsev, V. 2012. Analytical-Numerical Methods for Finding Hidden Oscillations in Dynamical Systems. Jyväskylä Studies in Computing, Vol. 158. Jyväskylä University Printing House.

Vaisberg, O., Vincke, O., Perrin, G., Sarda, J. \& Fay, J. 2002. Fatigue of drillstring: state of the art. Oil and Gas Science and Technology 57 (1), 7-37.

Viguié, R., Kerschen, G., Golinval, J.-C., McFarland, D. M., Bergman, L. A., Vakakis, A. F. \& van de Wouw, N. 2009. Using passive nonlinear targeted energy transfer to stabilize drill-string systems. Mechanical Systems and Signal Processing 23 (1), 148-169.

White, D. C. \& Woodson, H. H. 1968. Electromechanical Energy Conversion. The MIT Press.

van de Wouw, N., Nijmeijer, H. \& Mihajlović, N. 2005. Friction-induced limit cycling in flexible rotor systems: an experimental drill-string system. In Proc. International Design Engineering Technical Conference, Long Beach, California, USA.

Yakubovich, V., Leonov, G. \& Gelig, A. K. 2004. Stability of stationary sets in control systems with discontinuous nonlinearities. Singapore: World Scientific.

Zaremba, S. K. 1936. Sur les équations au paratingent. Bulletin des Sciences Mathématiques 60 (2), 139-160.

Zaretskiy, A. 2011. Mathematical models and stability analysis of synchronous motors. Master Thesis. University of Jyväskylä. 


\section{APPENDIX 1 LYAPUNOV FUNCTIONS METHOD}

The stability of solutions can be studied using a method developed by Lyapunov which involves special functions chosen suitably, known as Lyapunov functions (Lyapunov, 1950). It is not necessary to find the solution of a system in order to use this method. The following section explains the concepts of Lyapunov stability, Lyapunov functions, and describes the theorems used in the dissertation.

Following (Leonov, 2001; Krishenko, 2007), let us formulate the main notions and results. Consider the differential equation:

$$
\frac{d x}{d t}=f(t, x), \quad t \in \mathbb{R}^{1}, \quad x \in \mathbb{R}^{n}
$$

where $f(t, x)$ is a continuous vector-function: $\mathbb{R}^{1} \times \mathbb{R}^{n} \rightarrow \mathbb{R}^{n}$. Hereafter, we assume that all considered solutions $x\left(t, t_{0}, x_{0}\right)$ with initial data $x\left(t_{0}, t_{0}, x_{0}\right)=x_{0}$ are defined in the interval $\left(t_{0},+\infty\right)$.

Definition 1 Solution $x\left(t, t_{0}, x_{0}\right)$ of system (10) is Lyapunov stable, if for any number $\varepsilon>0$ there exists a number $\delta(\varepsilon)>0$ such as for all $y_{0}$, which satisfy the inequality $\left|x_{0}-y_{0}\right| \leq \delta(\varepsilon)$, the following relation holds true:

$$
\left|x\left(t, t_{0}, x_{0}\right)-x\left(t, t_{0}, y_{0}\right)\right| \leq \varepsilon \quad \forall t \geq t_{0} .
$$

Definition 2 If the solution $x\left(t, t_{0}, x_{0}\right)$ of system (10) is Lyapunov stable and there exists a number $\delta(\varepsilon)>0$ such as for all $y_{0}$, which satisfy the inequality $\left|x_{0}-y_{0}\right| \leq \delta(\varepsilon)$, the following relation holds true:

$$
\lim _{t \rightarrow+\infty}\left|x\left(t, t_{0}, x_{0}\right)-x\left(t, t_{0}, y_{0}\right)\right|=0,
$$

then the solution $x\left(t, t_{0}, x_{0}\right)$ is asymptotically stable.

Let us consider the case of the zero solution: $x\left(t, t_{0}, x_{0}\right) \equiv 0$. The generalised case is reduced to this particular case by the following change of variables $x=y+$ $x\left(t, t_{0}, x_{0}\right)$. However, this requires knowledge of the solution $x\left(t, t_{0}, x_{0}\right)$, something that is not always convenient.

Let us consider the function $V(x)$ differentiable in a certain neighbourhood of the point $x=0\left(V: \mathbb{R}^{n} \rightarrow \mathbb{R}^{1}\right)$, for which $V(0)=0$.

It is clear that if $x$ is replaced by the solution $x\left(t, t_{0}, x_{0}\right)$, then, according to the rules of differentiation of a composite function, we obtain the following identity:

$$
\frac{d V}{d t}=\sum_{i=1}^{n} \frac{\partial V}{\partial x_{i}} f_{i}(t, x)
$$

Here $x_{i}-i$-th component of the vector $x$ and $f_{i}-i$-th component of the vector function $f$. 
Theorem 3 (on asymptotic stability) Let there exist differentiable function $V(x)$ and continuous function $W(x)$, for which in certain neighborhood of the point $x=0$ the following conditions hold true:
1. $V(x)>0$ if $x \neq 0, V(0)=0$,
2. $\dot{V}(x) \leq W(x)<0$ if $x \neq 0$.

Then the zero solution of system (10) is asymptotically stable.

Theorem 4 (on instability) Let there exist differentiable function $V(x)$ and continuous function $W(x)$, for which in certain neighbourhood of the point $x=0$ the following conditions hold true:

1. $V(0)=0$ and for certain sequence $x_{k} \rightarrow 0$ when $k \rightarrow \infty$ inequalities $V\left(x_{k}\right)<0$ are fulfilled,

2. $\dot{V}(x) \leq W(x)<0$ when $x \neq 0$.

Then the zero solution of system (10) is Lyapunov unstable.

Definition 3 Let $x\left(t, t_{0}, y_{0}\right)$ be a solution of (10). Then the region of attraction is defined as the set of all points $y_{0}$ such that $\lim _{t \rightarrow+\infty} x\left(t, t_{0}, y_{0}\right)=0$.

Let us introduce certain notions that are necessary for further discussion. When talking about asymptotical stability of zero solution it is often interesting to determine on how far from it the trajectory can be and still tend to $x=0$.

Definition 4 If the equilibrium state of system (10) is asymptotically stable and its region of attraction is congruent to $\mathbb{R}^{n}$, then the equilibrium state is globally asymptotically stable.

Definition 5 Equilibrium state of system (10) is asymptotically stable in region $D$ if the region of attraction of this solution is congruent to $D$.

Definition 6 Function $V(x)$ is called positively definite, if for all $x \neq 0$

$$
V(x)>0
$$

and

$$
V(0)=0 .
$$

Definition 7 Function $V(x)$ is called negatively definite, if for all $x \neq 0$

$$
V(x)<0,
$$

and

$$
V(0)=0 .
$$

There are theorems on asymptotic stability by Barbashin and Krasovskii that are special cases of the theorem by La Salle (LaSalle, 1968). Let us formulate two of them (Barbashin and Krasovsky, 1952). 
Theorem 5 (the first theorem of Barbashin-Krasovsky) Let $x=0$ be an equilibrium state of system (10), defined in $\mathbb{R}^{n}$, and let there exist continuous and differentiable, positively definite and infinite for $\|x\| \rightarrow \infty$ function $V: \mathbb{R}^{n} \rightarrow \mathbb{R}^{1}$, derivative of which along the trajectories of system (10) is a negatively definite function. Then $x=0$ is a globally stable equilibrium state.

Theorem 6 (the second theorem of Barbashin-Krasovsky) Let $x=0$ be an equilibrium state of system (10), defined in $D$, and there exists continuous and differentiable, positively definite function $V: D \rightarrow \mathbb{R}^{1}$, for which $\dot{V}(x) \leq 0$ in $D$, and set $S=\{x \in$ $D: \dot{V}(x)=0\}$ doesn't contain full trajectories except of $x=0$. Then $x=0$ is an asymptotically stable equilibrium state. 


\section{APPENDIX 2 DIFFERENTIAL INCLUSIONS AND FILIPPOV DEFINITION}

All systems assessed in this study are right-hand discontinuous differential equations, due to modelling of the friction torque. To investigate these equations, it is necessary to introduce a new definition of solution that is applicable to these systems. Continuing the work of (Andronov et al., 1966; Yakubovich et al., 2004; Filippov, 1960) below, the friction in mechanical systems will be considered, and reason for which the well-known definition of solution of an ordinary differential equation doesn't work for discontinuous systems will be explained. The notion of the differential inclusion will be introduced, along with the Filippov definition for systems of differential equations with discontinuous right-hand sides.

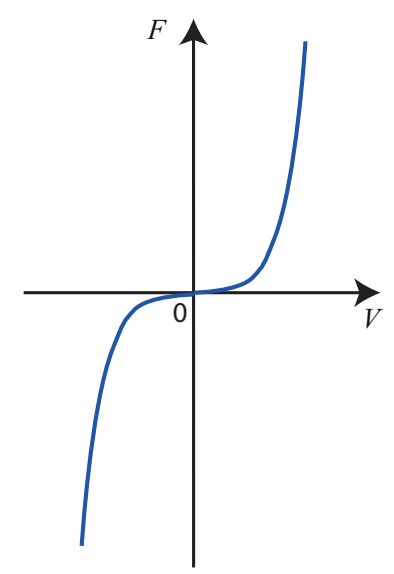

FIGURE 12 Viscous friction

Credit for the discovery of the theory is usually given to the French mathematician Marchaud (Marchaud, 1936) and the Polish mathematician Zaremba (Zaremba, 1936). Later on, Filippov (Filippov, 1960, 1985, 1988) introduced definition of a solution for a discontinuous system. That encompasses other wellknown definitions of discontinuous system solutions encountered in the problem in this study.

\section{Mechanical system with a dry friction}

As proven in (Andronov et al., 1966), relationship between the work required to overcome friction and the speed can be established. This relationship between work and friction when the body is moving in fluid is completely distinct from that of the friction between the body and any solid surface. In the first case (known as "viscous friction"), the work is proportional to the speed; that is, if the speed decreases, the work decreases as well and it can be made arbitrarily small. In the case of "dry friction", however, the work is only partially dependent on the speed. Regardless of how slow the body is moved, some work is done by 


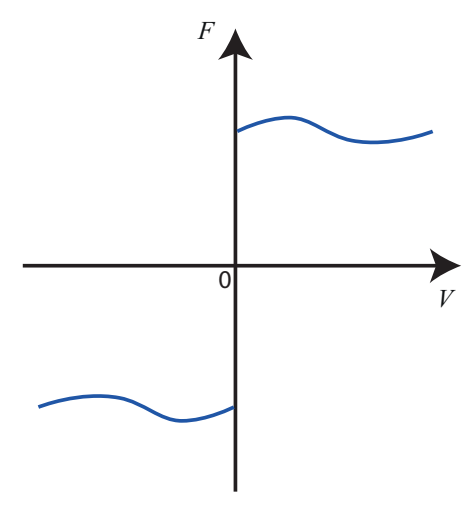

FIGURE 13 Dry friction

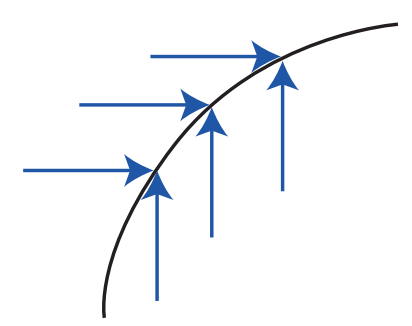

FIGURE 14 Slope field in the neighborhood of discontinuity surface: the sliding mode

the system, i.e., the friction force has a finite value even when the speed is arbitrary small. Furthermore, as the friction force is always applied in the direction opposite to the velocity, the friction force changes sign when passing through zero. In the case of the "viscous friction", the friction force changes sign as it passes through zero without a jump (Fig. 12, (Andronov et al., 1966)).

With "dry friction", the friction force on both sides tends to different finite limits as the speed tends to zero. These limits are opposite in sign, but equal in absolute value. It follows, then, that the function is discontinuous at zero (Fig. 13, (Andronov et al., 1966)).

Thus, mathematical models of mechanical systems with the Coulomb friction, obtained from knowing the mechanics of the systems of rigid bodies, are differential equations, the right-hand sides of which are discontinuous functions with respect to generalized velocities (the friction force changes abruptly when the direction of the motion changes) (Bothe, 1999; Fečkan, 1997, 1999; Filippov, 1988; Kunze, 2000; Kunze and Küpper, 1997).

The sliding mode is one of the operational modes of a system with dry friction, which occurs when phase trajectories are directed towards each other in the neighborhood of the discontinuous surface of the control function (see Fig. 14, (Gelig et al., 1978)). When the function comes into contact with the discontinuity, for an arbitrarily small time interval, the image point is incapable of moving along any trajectory adjacent to the surface (should any displacement occur, there is always movement that returns an affix on the discontinuity surface). Another 


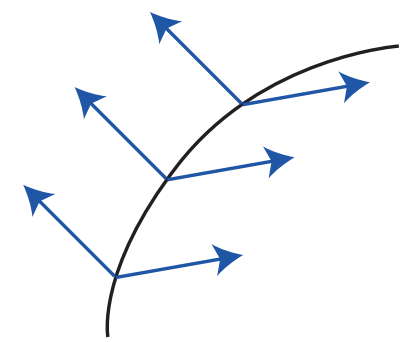

FIGURE 15 Slope field in the neighborhood of discontinuity surface: the solution moves away from the discontinuity surface

scenario may also occur: the opposite happens, and the solution doesn't reach the corresponding part of the discontinuity surface as time progresses (see Fig. 15, (Gelig et al., 1978)).

\section{Justification of the need to generalize the notion of solution of differential equation}

The classical definition of solutions of differential equation reads as (Filippov, 1985).

Definition 8 Solution of differential equation

$$
\dot{x}=f(x, t)
$$

with continuous right-hand side is a function $x(t)$, which has derivative everywhere on this interval and satisfies this equation.

Furthermore, the equation with a continuous right-hand side is equivalent to the following integral equation

$$
x(t)=\int f(t, x(t)) d t+C .
$$

The definition 8 does not work when the differential equation is right-hand discontinuous. However, for cases where $f(t, x)$ is discontinuous for $t$ and continuous for $x$, the functions satisfying integral equation may be called solutions of the equation. When this occurs, solutions from one side of discontinuity surface $S$ go to $S$, from the other side they go off $S$ (trajectories puncture the surface), see Fig. 16, (Gelig et al., 1978).

Solution $x(t)$, which falls for $t=t_{0}$ into the discontinuity surface $S$, extends uniquely for $t>t_{0}$ and close to $t_{0}$; by intersecting $S$ the solution satisfies the equation everywhere except the point of intersection in which the solution doesn't have a derivative. In another case, when the solution approach the discontinuity surface $S$ from both sides (trajectories merge - the sliding mode), this definition of solution is meaningless, because it tells us nothing about the behavior of the solution on the surface $S$. 


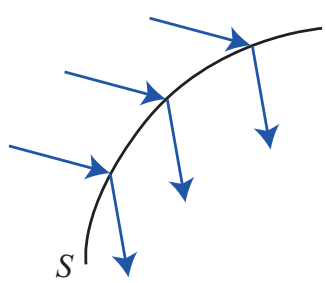

FIGURE 16 Slope field in the neighborhood of discontinuity surface: trajectories puncture the surface $S$

It is necessary to give such definition of the solution which would embody these both cases and which formulation would not be dependent on the lines' position and discontinuity surfaces.

\section{Definition of solution}

Consider the equation of the system in the vector notation

$$
\dot{x}=f(t, x),
$$

with a piecewise continuous function $f$ in the region $G ; x \in \mathbb{R}^{n}, M$ - set (of measure zero) of discontinuity point of function $f$.

Most of the well-known definitions of solution of equation (15) could be described in the following way. For each point $(t, x)$ of the region $G$ set $F(t, x)$ in $n$-dimensional space is introduced. If at the point $(t, x)$ function $f$ is continuous, then the set $F(t, x)$ consists of one point, which is congruent to the value of the function $f$ at this point. If $(t, x)$ is a discontinuity point of the function $f$, then the set $F(t, x)$ is defined in certain chosen way.

Definition 9 Solution of equation (15) is called the solution of the differential inclusion

$$
\dot{x} \in F(t, x),
$$

i.e., absolutely continuous vector function $x(t)$, defined on the interval or segment $I$, for which almost everywhere on $I \quad \dot{x} \in F(t, x)$.

In other words, the solution of the differential equation (15) is defined as a function which derivative $\dot{x}=d x / d t$ may have any values from a certain set $F(t, x)$. Sometimes (16) are called differential equations with a set-valued right-hand side. A function is called a set-valued function and we emphasize that $F(t, x)$ is a set. If for all $(t, x)$ the set $F(t, x)$ contains only one point, then (16) is an ordinary differential equation. The function $F(t, x)$ is called one-valued at the point $\left(t_{0}, x_{0}\right)$, if the set $F\left(t_{0}, x_{0}\right)$ contains one point.

The most common definition of the solution of discontinuous system is Filippov definition. (Filippov, 1960, 1985, 1988).

\section{Extending convex definition}


For every point $(t, x) \in G$ let $F(t, x)$ be the minimal convex closed set which contains all limit vector-functions $f\left(t, x^{*}\right)$; when $\left(t, x^{*}\right) \notin M, x^{*} \rightarrow x, t=$ const. We call the solution of system (15) a solution of differential inclusion (16) with the just constructed $F(t, x)$. Since $M$ is a set of measure zero, for almost all $t \in I$ the measure of the section of set $M$ with the plane $t=$ const is zero. For these $t$, the set $F(t, x)$ is defined for all $(t, x) \in G$. At the points of continuity for function $f$, a set $F(t, x)$ consists of one point $f(t, x)$ and the solution satisfies equation (15) in the ordinary sense. If the point $(t, x) \in M$ lies on the boundaries of two or more regions $G_{1}, \ldots, G_{k}$ of plane $t=$ const, then the set $F(t, x)$ is a segment, convex polygon or polyhedron with vertexes $f_{i}(t, x), i \leq k$, where

$$
f_{i}(t, x)=\lim _{\substack{\left(t, x^{*}\right) \in G_{i} \\ x^{*} \rightarrow x}} f\left(t, x^{*}\right) .
$$

All the points $f_{i}(t, x)(i=1, \ldots, k)$ are contained in $F(t, x)$, but not necessarily all of them are vertexes.

Definition 10 (Filippov definition) Vector-function $x(t)$, defined on the interval $J$, is called a solution of system (15), if it is absolutely continuous and if for almost all $t \in J$ and for all $\delta>0$ the vector $\dot{x}(t)$ belongs to the minimal convex closed set (n-dimensional space), which contains all the values of the vector function $f\left(t, x^{*}\right)$, when $x^{*}$ runs through almost entire $\delta$-neighborhood of the point $x(t)$ in the space $X$ (for a fixed $t$ ), that is, through the entire neighborhood, except of the set of measure zero.

Such definition outlines the unique extension of the solution on the discontinuity surface. Let us consider the case when the function $f(t, x)$ is discontinuous on a smooth surface $S$, defined by the equation $s(x)=0$. The surface $S$ divides its neighborhood in the space into the regions $G^{-}$and $G^{+}$. Let for $t=$ const and for approximation $x^{*}$ for $x \in S$ from regions $G^{-}$and $G^{+}$the function has limit values

$$
\begin{aligned}
& \lim _{\substack{x^{*} \in G^{-} \\
x^{*} \rightarrow x}} f\left(t, x^{*}\right)=f^{-}(t, x), \\
& \lim _{\substack{x^{*} \in G^{+} \\
x^{*} \rightarrow x}} f\left(t, x^{+}\right)=f^{+}(t, x) .
\end{aligned}
$$

Then the set $F(t, x)$, mentioned in the definition of extension, is the segment which connects endings of the vectors $f^{-}(t, x)$ and $f^{+}(t, x)$, which start at $x$.

- If for $t \in I$ the segment lies on one side of the surface $P$, which is tangent to the surface $S$ at the point, then the solutions for those $t$ go from one side of the surface $S$ to its other side (Fig. 17, (Filippov, 1985)).

- If this segment crosses the surface $P$, the crossing point is the end of the vector $f^{0}(t, x)$, which defines the speed of the motion

$$
\dot{x}=f^{0}(t, x)
$$

along the surface $S$ in space $X$ (Fig. 18, (Filippov, 1985)).

Note that the vector is tangent to $S f^{0}(t, x) \in P$, so, $f^{0}(t, x) \in F(t, x)$. This means that the function $x(t)$, which satisfies equation (19) due to the extension, 


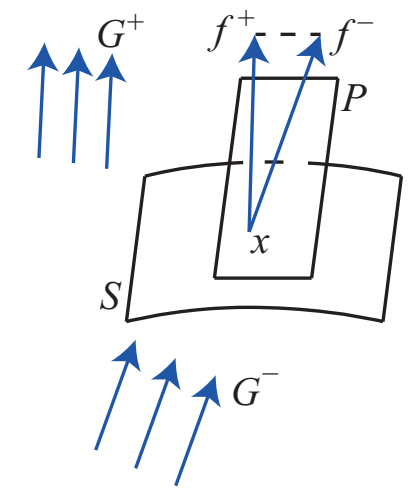

FIGURE 17 The solution goes from one side of the surface $S$ to its other side

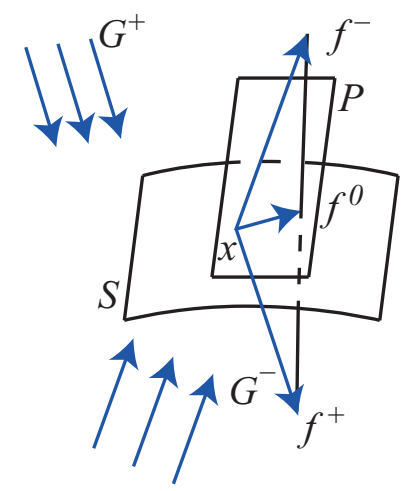

FIGURE 18 Motion of the solution along the surface $S$ 
is the solution of equation (15). This implies that $x(t)$, which on this part of the considered time interval passes in the area $G^{-}$(or in the area $\left.G^{+}\right)$and satisfies equation (15); on the remaining part it goes along the surface $S$ and satisfies equation (19), it is also considered as a solution of (15) in the sense of the definition of extension introduced above.

In equation (19) $f^{0}=\alpha f^{+}+(1-\alpha) f^{-}$,

$$
\alpha=\frac{f_{N}^{-}}{f_{N}^{-}-f_{N}^{+}}, \quad(0 \leq \alpha \leq 1),
$$

$f_{N^{\prime}}^{+} f_{N}^{-}$are vectors projections of $f^{+}$and $f^{+}$to the normal of the surface $S$ at the point $x$ (the normal is oriented towards the direction of $G^{+}$).

- If the whole segment with the endings $f^{-}$and $f^{+}$lies on the surface $P$, then the movement speed $f^{0}$ on discontinuity surface $S$ is multi-valued.

For $f^{0} \neq f^{-}, f^{0} \neq f^{+}$there is a sliding mode, which was discussed before. Let the ideal sliding mode equation look as equation (19). Calculating $\alpha$ for $f^{0}=$ $\alpha f^{+}+(1-\alpha) f^{-}$from the condition grad $S \cdot f^{0}=0$, we find the equation

$$
\dot{x}=\frac{\operatorname{grad} S \cdot f^{-}}{\operatorname{grad} S \cdot\left(f^{-}-f^{+}\right)} f^{+}-\frac{\operatorname{grad} S \cdot f^{+}}{\operatorname{grad} S \cdot\left(f^{-}-f^{+}\right)} f^{-},
$$

with the help of which we define the motion in the sliding mode (the initial data for (21) is chosen on the discontinuous surface, i.e., $S(x(0))=0$ ).

The connection of the theory of equations (15) with discontinuous righthand side to the theory of differential inclusions (16) is obvious. If there is equation (17) with discontinuous function $f(t, x)$, we need to replace its value $f\left(t_{0}, x_{0}\right)$ in the discontinuity point $\left(t_{0}, x_{0}\right)$ with a certain set. This set should be limited, convex, and self-contained. Furthermore, it should contain all limit values $f(t, x)$ when $(t, x) \rightarrow\left(t_{0}, x_{0}\right)$. After such change of variables (for any discontinuity point) instead of (15) we obtain differential inclusion (16), in which a set-valued function satisfies the above stated requirements.

This extension can be applied to systems with a small delay of a certain type and to some systems with a dry friction including the systems considered in this study. 


\section{APPENDIX 3 NUMERICAL METHODS OF STABILITY INVESTIGATION OF DISCONTINUOUS SYSTEMS}

The models studied in this work use equations with discontinuous right handsides. Hence, a special method for numerical computation of their solutions is required. In what follows, we are going to provide a brief description of one of such methods following the works (Piiroinen and Kuznetsov, 2008; Kuznetsov et al., 2003).

\section{The event-driven simulation method}

In some cases it is definitely possible to find explicit expressions for the solutions of the ordinary differential equation that describe sliding if the vector fields in the non-sliding regions are given. For example, this is the case when we consider low order linear systems. However, in the case of the above models of the drilling systems actuated by an induction motor, the idea is to present a numerical algorithm where we only provide different vector fields and information about the discontinuity surface, and then the vector fields for the sliding regions are automatically computed. The method that has been chosen here for modeling the systems with a discontinuous right-hand side is similar to the hybrid system approach, where the integrations of smooth ordinary differential equations are mixed with discrete maps and vector field switches. In practice, this means that an initial value problem is solved for one of the possible smooth dynamical systems until the trajectory of the solution reaches one of the predefined surfaces. At such a point, the vector field is possibly switched, depending on the state at that instance. It is very important to have a reliable ODE solver that is supplemented by an accurate routine to locate discontinuity surface and the tangent surface crossings. In what follows, a surface crossing will be called an event and a scalar function defining an event surface will be referred to as the event function. We will assume here the existence of event detection routines. For instance, in MATLAB (Higham and Higham, 2005) the event detection routines are built-in and can easily be used together with the likewise built-in ODE solvers in order to integrate trajectories and to locate events along them as precisely as the accuracy of MATLAB permits (for more details of the MATLAB ODE routines, see (Shampine and Reichelt, 1997; Ashino et al., 2000)). However, standard methods, for example, the so-called secant type methods, can easily be implemented and have proven to be fast and reliable. The type of events which need to be detected also plays an important role in how to numerically deal with them and how sensitive the event detection should be. Let us introduce the basic ideas behind the simulation algorithm for one discontinuity surface and a description on how the algorithm works following (Piiroinen and Kuznetsov, 2008).

Let us consider a general dynamical system:

$$
\dot{x}=f(x), \quad x \in \mathbb{R}^{n},
$$




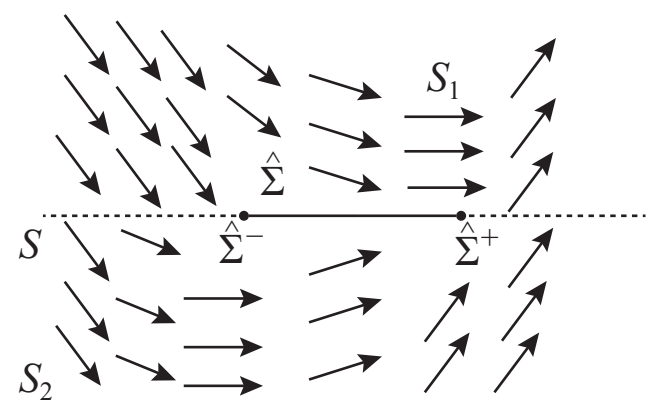

FIGURE 19 The vector fields $F_{1}$ and $F_{2}$ near a stable sliding region $\hat{\Sigma}$.

here the vector field $f(x)$ is either smooth or piecewise smooth. Assume that the state space consists of only two regions, $S_{1}$ and $S_{2}$, separated by a discontinuity surface $S$, which is defined by a smooth scalar function $h(x)$ such that

$$
S=\left\{x \in \mathbb{R}^{n} \mid h(x)=0\right\},
$$

and where

$$
S_{1}=\left\{x \in \mathbb{R}^{n} \mid h(x)>0\right\}
$$

and

$$
S_{2}=\left\{x \in \mathbb{R}^{n} \mid h(x)<0\right\} .
$$

Dynamical system (22) can be rewritten as

$$
\dot{x} \in \begin{cases}F_{1}(x), & \text { if } x \in S_{1} \\ F_{2}(x), & \text { if } x \in S_{2}\end{cases}
$$

where $F_{1}$ and $F_{2}$ are sufficiently smooth. Let us also assume that $F_{1}$ and $F_{2}$ are defined in the whole state space.

The motion is said to be sliding if both vector fields $F_{1}$ and $F_{2}$ are locally pointing away from or pointing towards the discontinuity surface $S$ (see Fig. 19). We call the sliding surface the open subset $\hat{\Sigma}$ of the surface $S$ where the vector fields are both pointing towards or away from $S$. In Fig. 19 the sliding surface $\hat{\Sigma}$ which is a subset of $S$ is a line segment between two points, $\hat{\Sigma}^{+}$and $\hat{\Sigma}^{-}$.

Let us define the Lie derivative $\mathcal{L}_{F}(h)(x)$ of a smooth function $f(x)$ along a smooth vector field $F(x)$ as

$$
\mathcal{L}_{F}(h)(x):=\left.\frac{d}{d t} h(\xi(t))\right|_{t=0}=\left.\frac{d h(x)}{d x} \frac{\xi(t)}{d t}\right|_{t=0}=\left\langle\frac{h(x)}{d x}, F(x)\right\rangle,
$$

where $\xi(t)$ is a solution of the equation $\dot{\xi}=F(\xi)$ with initial data $\xi(0)=x$.

Thus, sliding surface $\hat{\Sigma}$ is stable if

$$
\mathcal{L}_{F_{1}-F_{2}}(h)(x)<0, \quad x \in \hat{\Sigma},
$$

and sliding surface $\hat{\Sigma}$ is unstable if

$$
\mathcal{L}_{F_{1}-F_{2}}(h)(x)>0, \quad x \in \hat{\Sigma} .
$$




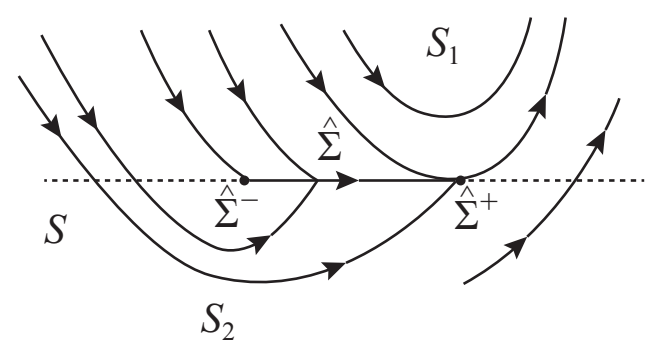

FIGURE 20 Some trajectories corresponding to the vector fields $F_{1}$ and $F_{2}$ near a stable sliding region $\hat{\Sigma}$

According to Utkin's equivalent control (Utkin, 1992) we can extend the dynamical system (26) in order to include the vector field on the sliding surface such that

where

$$
\dot{x}=F_{12}(x), \quad x \in \hat{\Sigma},
$$

$$
F_{12}(x)=\frac{F_{1}(x)+F_{2}(x)}{2}+\frac{F_{2}(x)-F_{1}(x)}{2} \mu(x),
$$

and $-1 \leq \mu \leq 1$. Due to the fact that the motion is constrained to $\hat{\Sigma}, F_{12}$ must be tangent to $\hat{\Sigma}$, i.e. $\mathcal{L}_{F_{12}}(h)(x)$, which yields

$$
\mu(x)=-\frac{\mathcal{L}_{F_{1}+F_{2}}(h)(x)}{\mathcal{L}_{F_{2}-F_{1}}(h)(x)} .
$$

Notice that $F_{12}=F_{1}$ when $\mu(x)=-1$ and $F_{12}=F_{2}$ when $\mu(x)=1$, and also $\mathcal{L}_{F_{2}-F_{1}}(h)(x) \neq 0$ for $x \in \hat{\Sigma}$ since the vetoer fields always either point toward or away from the discontinuity surface. Thus the surfaces defining the borders of the sliding surface are as follows:

$$
\hat{\Sigma}^{-}=\{x \in \hat{\Sigma} \mid \mu(x)=-1\}
$$

and

$$
\hat{\Sigma}^{+}=\{x \in \hat{\Sigma} \mid \mu(x)=1\} .
$$

These points will be referred to as tangent surfaces.

By concatenating standard solutions in $S_{1}$ and $S_{2}$ and sliding solutions in $\hat{\Sigma}$ (See Fig. 20) let us define the solutions of system (26). To assure the uniqueness of such a solution, the assumption that it does not visit points of $S$, where both vectors $F_{1}$ and $F_{2}$ are tangent to $S$, is required. We are going to call such solutions and their corresponding orbits generic.

Finally, let us discuss a relationship between the commonly used Filippov's convex method (Filippov, 1988) and the above described construction. As was mentioned in Appendix 2 original Filippov approach consists of replacing (26) by the differential inclusion

$$
\dot{x} \in \begin{cases}F_{1}(x), & \text { if } x \in S_{1} \\ \overline{C O}\left(F_{1}(x), F_{2}(x)\right), & \text { if } x \in S \\ F_{2}(x), & \text { if } x \in S_{2}\end{cases}
$$




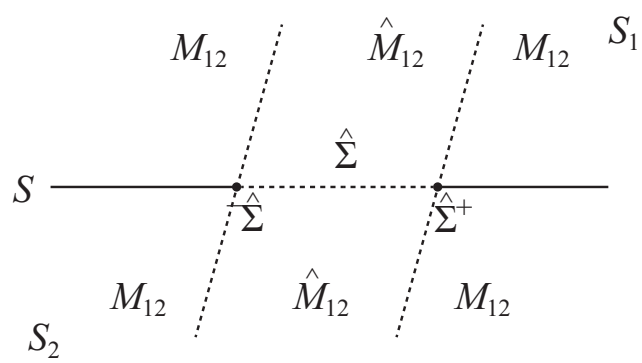

FIGURE 21 Different regions that the state space is divided into in a neighbourhood of the sliding surface $\hat{\Sigma}$

where $\overline{c o}\left(F_{1}(x), F_{2}(x)\right)$ is the minimal closed convex set which contains $F_{1}$ and $F_{2}$; that is

$$
\overline{c o}\left(F_{1}(x), F_{2}(x)\right)=\left\{f \in \mathbb{R}^{n}: f=F_{1}+\lambda\left(F_{2}-F_{1}\right), \lambda \in[0,1]\right\} .
$$

A solution to this differential inclusion is an absolutely continuous function $x(t)$ that satisfies (35) for almost all $t$ from its definition domain. Assuming smoothness of $F$ and $h$, Theorem 2 by Filippov (Filippov, 1988) (Chapter 2, pp. 110-111) implies forward uniqueness of those solutions of (35), which do not visit unstable sliding surfaces, and those points of sliding surface $S$ where both vectors $F_{1}$ and $F_{2}$ are tangent to $S$. Moreover, this unique solution is the same as the one constructed above. It should be noted that the solutions constructed with help of Filippov's approach starting at unstable sliding surfaces are not unique, while they generically have this property in our formulation, where they are constrained to $\hat{\Sigma}$. This difference is not important in most applications, since solutions which start away from the unstable sliding surface can never reach it.

Let us rewrite the full dynamical system with one discontinuity surface $S$ as

$$
\dot{x} \in \begin{cases}F_{1}(x), & \text { if } x \in S_{1} \\ \hat{F}_{12}, & \text { if } x \in S, \\ F_{2}(x), & \text { if } x \in S_{2}\end{cases}
$$

where the sliding vector field $F_{12}$ is given by (31). In addition, since the dynamics depends on $\hat{\Sigma}$ during sliding, we substitute $F_{12}(x)$ by its regularisation $\hat{F}_{12}(x)$ in order to avoid drift away from $\hat{\Sigma}$.

The state space for Filippov system with one discontinuity surface can be locally divided into three disjoint regions, namely, $S_{1}, S_{2}$ and $S$. Further, the state space can also be divided into two regions, $\hat{M}_{12}$ and $M_{12}$, by the two extended tangent surfaces $S^{-}$and $S^{+}$, which are defined by

$$
\begin{gathered}
S^{-}=\left\{x \in \mathbb{R}^{n} \mid \mu(x)=-1\right\}=\left\{x \in \mathbb{R}^{n} \mid \mathcal{L}_{F_{1}}(h)=0\right\}, \\
S^{+}=\left\{x \in \mathbb{R}^{n} \mid \mu(x)=1\right\}=\left\{x \in \mathbb{R}^{n} \mid \mathcal{L}_{F_{2}}(h)=0\right\},
\end{gathered}
$$


where $\mu$ is defined as in equation (32) (see Fig. 21). By using (38) and (39) the two regions $\hat{M}_{12}$ and $M_{12}$ can be defined as

$$
\hat{M}_{12}=\left\{x \in \mathbb{R}^{n}|| \mu(x) \mid<1\right\}
$$

and

$$
M_{12}=\left\{x \in \mathbb{R}^{n}|| \mu(x) \mid \geq 1\right\} .
$$

One can notice the similarity with the tangent surfaces defined in equations (33) and (34). Also, since it is assumed that $F_{1}$ and $F_{2}$ are defined everywhere in the state space, $\mu$ is defined everywhere except for points where both $F_{1}$ and $F_{2}$ are tangent to the surface $h(x)=$ const.

This division into disjoint subregions makes it relatively easy to implement in a numerical algorithm and reduces the number of checks that should be made every time the discontinuity surface $S$ is crossed. Also, taking into account the fact that we are always looking for the surfaces given by $\mathcal{L}_{F_{1}}(h)(x)=0$ and $\mathcal{L}_{F_{2}}(h)(x)=0$ it makes the algorithm more robust when locating the events for orbits that hit the discontinuity surface almost tangentially.

During the simulation of Filippov systems using an event-driven scheme it is important to locate events, for example, discontinuity surface or a tangent surface crossing, as accurately as possible (within a given tolerance). Therefore, to make an automatic algorithm robust, we need to predefine specific events as region-dependent. In case it is assumed that a system has a total of $m$ possible events in each region then an event list $e(x, t)$ can be defined as

$$
e(x, t)=\left(e_{1}(x, t), \ldots, e_{m}(x, t)\right),
$$

where each element $e_{k}(x, t) \in \mathbb{R}$ is an event function that defines an event surface that can be reached by the state vector or the time.

Let us define the event functions as

$$
e_{1}(x, t):=h(x), \quad e_{2}(x, t):=\mathcal{L}_{F_{1}}(h)(x), \quad e_{3}(x, t):=\mathcal{L}_{F_{2}}(h)(x),
$$

(cl. equations(38) and (39)).

In order for the solver to know what vector field to use and what events to look for, we will introduce a number of event variables. So, to keep track of which of the regions $S_{1}, S_{2}$ and $\hat{\Sigma}$ the state variable $x(t)$ is in the event variables $s_{1}, s_{2}$ and $s_{3}$ are introduced respectively. Further, to look after the state variable is in $M_{12}$ of $\hat{M}_{12}$ we are introducing the event variables $s_{4}$ and $s_{5}$, respectively. Letting $s=\left(s_{1}, s_{2}, s_{3}, s_{4}, s_{5}\right)^{T}$ and using the same state division as in Fig. 21 the event variables can be given the following values

$$
\begin{gathered}
s_{1}(x) \in\left\{\begin{array} { l l } 
{ 1 , } & { \text { if } x \in S _ { 1 } } \\
{ - 1 , } & { \text { if } x \notin S _ { 1 } , }
\end{array} \quad s _ { 2 } ( x ) \in \left\{\begin{array}{ll}
1, & \text { if } x \in S_{2} \\
-1, & \text { if } x \notin S_{2},
\end{array}\right.\right. \\
s_{3}(x) \in \begin{cases}1, & \text { if } x \in \hat{\Sigma} \\
-1, & \text { if } x \notin \hat{\Sigma},\end{cases}
\end{gathered}
$$




$$
s_{4}(x) \in\left\{\begin{array} { l l } 
{ 1 , } & { \text { if } x \in M _ { 1 2 } } \\
{ - 1 , } & { \text { if } x \notin M _ { 1 2 } , }
\end{array} \quad s _ { 5 } ( x ) \in \left\{\begin{array}{ll}
1, & \text { if } x \in \hat{M}_{12} \\
-1, & \text { if } x \notin \hat{M}_{12} .
\end{array}\right.\right.
$$

The event parameters are changed at the even depending on in what region $x(t)$ is in and to what region it continues. For instance, assume $x \in S_{1} \cup \hat{M}_{12}$ before it crossed the discontinuity surface $S$ then we obtain

$$
s=(1,-1,-1,-1,1)
$$

before the crossing and

$$
s=(-1,-1,1,-1,1)
$$

after. This means that the orbit is sliding along $\hat{\Sigma}$ after the surface crossing and this information is passed to the solver so that during the solving process the correct vector field is used.

Continuing this discussion, each of our original event functions $e_{k}$ can be seen as one of two different kinds, namely $e_{k}^{+}(x, t)$ and $e_{k}^{-}(x, t)$, where the former corresponds to one in which the surface crossings are only detected when $e_{k}$ is increasing and the latter when $e_{k}$ is decreasing. The MATLAB code built according to this algorithm is presented in Appendix 6.

Let us explain the importance of special numerical methods for modelling the systems with discontinuous right-hand side.

Consider the following system of equations which describes the operation of the Watt governor with the dry friction model (Andronov and Mayer, 1947; Yakubovich et al., 2004; Gelig et al., 1978):

$$
\begin{aligned}
& \dot{y}_{1}=-A y_{1}+y_{2}-\operatorname{sign}\left(y_{1}\right), \\
& \dot{y}_{2}=-B y_{1}+y_{3} \\
& \dot{y}_{3}=-y_{1} .
\end{aligned}
$$

It is well-known that the sliding region of system (47) is globally stable when $A B>1$ (Yakubovich et al., 2004; Gelig et al., 1978). Consider $A=1.5, B=1.1$ and $y_{1}(0)=-0.5, y_{2}(0)=1, y_{3}(0)=1$.2. If the modelling is conducted without special methods for discontinuous systems (see Fig. 22) the small oscillations appear in the system (47) (see Fig. 22, b). On the other hand, if the event-driven simulation method is used there are no such oscillations and the trajectory is stable (see Fig. 23).

This example demonstrates that careful treatment of solutions of systems with discontinuous right-hand side is required. 


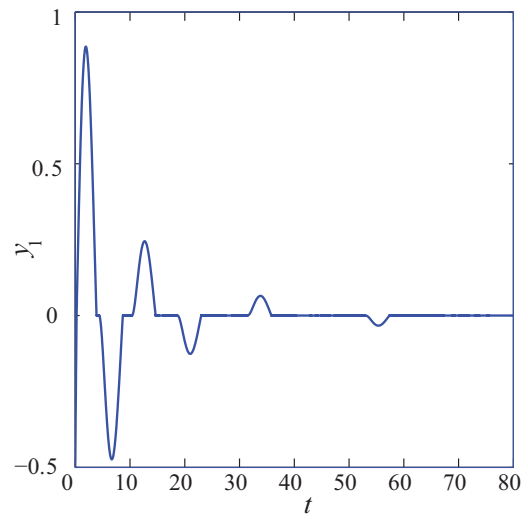

a)

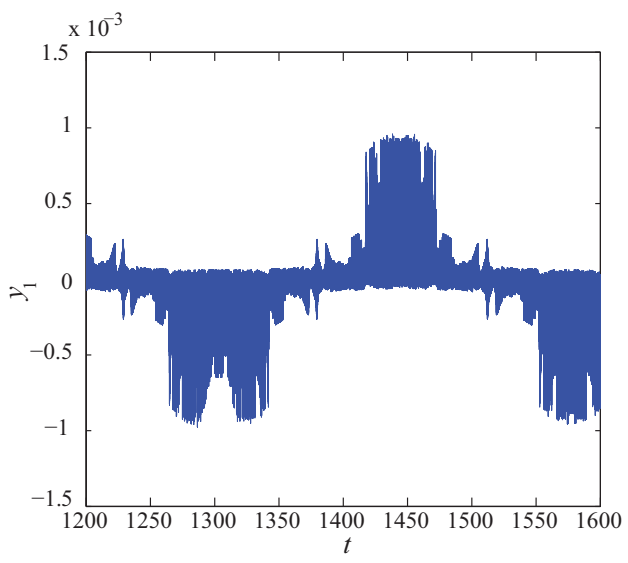

b)

FIGURE 22 Numerical modelling of the Watt governor without using special methods for systems with discontinuous right-hand side.

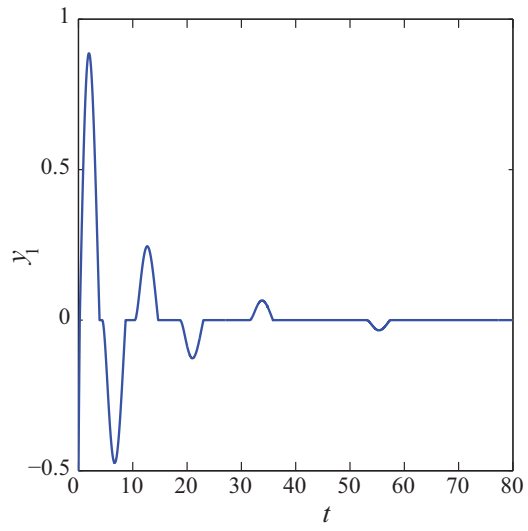

a)

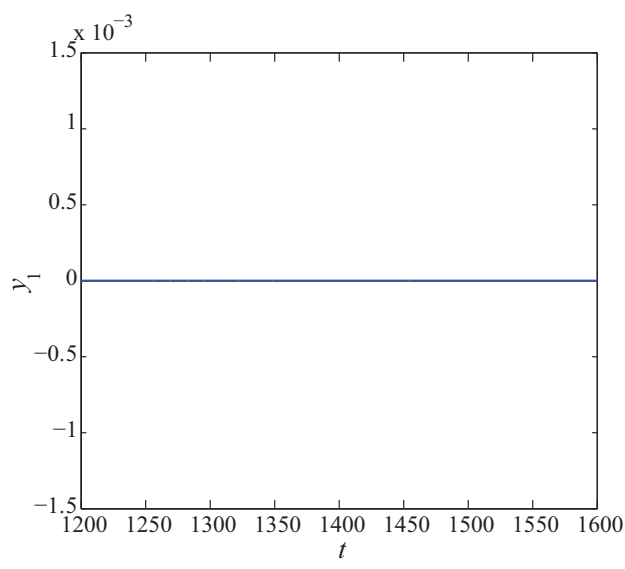

b)

FIGURE 23 Numerical modelling of the Watt governor with help of the event-driven simulation method. 


\section{APPENDIX 4 MATHEMATICAL MODEL OF INDUCTION MOTOR}

In what follows, we are going to provide a brief derivation of a system of equations describing a mathematical model of the induction motor with a wound rotor. The full version of this derivation can be found in (Leonov et al., 2014; Leonov and Solovyeva, 2012).

Currently, the methods of research and design of asynchronous motors based on mathematical modeling have become widespread (Bespalov et al., 2002; Bespalov, 1992; Golubev and Zikov, 2003; Gruzov, 1953; Kopilov et al., 2002; Kopilov, 2001b,a; Moshinsky and Petrov, 2001; Moshinsky and T., 2007; Moshinsky and Petrov, 2007; Pankratov and Zima, 2003; Sipaylov and Loos, 1980; Hrisanov and Brxhezinsky, 2003). Both Russian and foreign researchers have made great contribution to the development and establishment of scientific methods of calculation of induction motors, among them: Adkins, Bespalov, Blondel, Woodson, Glebov, Gorev, Danilevich, Ivanov-Smolensky, Ilinskiy, Kazovsky, Kovacs, Kononenko, Kopylov, Kostenko, Kron, Luther, Park, Petrov, Postnikov, Radin, Raz, Sipailov, Soroker, Treschev, White, Filtz and others.

The basic constructive elements of induction electrical machines are stationary stator and rotating rotor. The windings are located on the stator and the rotor. Stator winding is arranged in such a way that it generates a rotating magnetic field when fed with alternate current.

Consider the induction motor with a wound rotor (Drury, 2001) shown in Fig. 24. In the simplest case, a wound rotor winding consists of three coils, each consists of several turns of insulated conductor. Furthermore, one considers induction motors with wound rotor, when a rotor winding is short-circuited and no external devices are connected. A working gear is connected to the rotor shaft (in our case, it is a drill-string). Thus, the induction motor, by transforming the electric energy into the mechanical one, imparts rotational motion to the working gear via shaft.

The classic derivation of expressions for the currents in rotor winding and the electromagnetic torque of induction motor are based on the following simplifying assumptions (Popescu, 2000; Leonhard, 2001; Skubov and Khodzhaev, 2008):

I It is assumed that the magnetic permeability of the stator and rotor iron is equal to infinity. This assumption makes it possible to use the principle of superposition for the determination of the magnetic field, generated by the stator;

II one may neglect energy losses in electrical steel, i.e., the losses related to motor heating, magnetic hysteresis, and whirling currents;

III one does not take into account saturation of the rotor iron, i.e. the current of any force can run in rotor winding; 


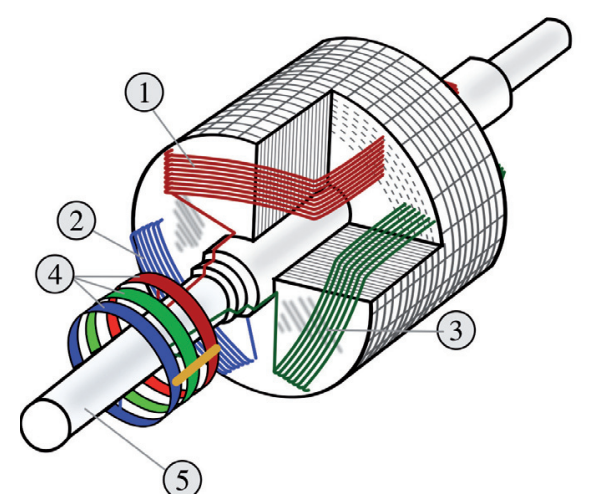

FIGURE 24 Wound rotor of induction motor: 1 - the first coil with the current $i_{1}, 2$ - the second coil with the current $i_{2}, 3$ - the third coil with the current $i_{3}, 4$ - slip rings, 5 - rotor shaft

IV one may neglect the effects arising at the ends of rotor winding and in rotor slots, i.e., one may assume that the magnetic field is distributed uniformly along the circumference of the motor;

Let us make an additional assumption:

V Stator windings are fed by a powerful outlet of sinusoidal voltage.

Then, following the works (Adkins, 1957; White and Woodson, 1968; Skubov and Khodzhaev, 2008), due to the last assumption, the effect of rotor currents on stator currents may be ignored. Thus, a stator generates a uniformly rotating magnetic field with constant magnitude. So, one may assume that magnetic induction vector is constant in magnitude and rotates with a constant angular velocity. This assumption is due to the classical ideas of Tesla and Ferraris and allows one to consider dynamics of induction motor from the point of view of its rotor dynamics (Leonov, 2006; Leonov and Solovyeva, 2012; Leonov et al., 2013).

Suppose that the magnetic field rotates clockwise. One introduces uniformly rotating coordinates, rigidly connected with the vector magnetic induction, and considers the motion of wound rotor in this coordinate system. Also, suppose that the positive direction of the rotation axis of the rotor coincides with the direction of the rotation of the magnetic induction vector.

The rotating magnetic field crosses rotor winding and, by the law of electromagnetic induction, it induces electromotive force (EMF) in it. Thus, taking into account the number of turns, EMF in coils is equal to

$$
\varepsilon_{k}=-n S B \cos \left(\frac{\pi}{2}-\theta-\frac{2(k-1) \pi}{3}\right) \dot{\theta}, \quad k=1,2,3 .
$$

Here $B$ is the inductance of the magnetic field, $n$ is the number of turns in each coil, $S$ is a cross-sectional area of coil, $\theta$ is a mechanical angle of rotation of rotor. 
The EMF induces a variable current in the rotor winding. According to Ampere's force law, as a result of the interaction of currents in coils with rotating magnetic field, electromagnetic forces arise. Electromagnetic forces generate electromagnetic rotating moment, under which the rotor begins to rotate with a certain frequency.

Using Ampere's force law for calculating electromagnetic forces and taking into account the number of turns in coil and positive direction of the rotor rotation axis, it follows that the generated rotating electromagnetic torque, acting on a coil with the current $i_{k}$, is equal to

$$
M_{k}=n S B \cos \left(\frac{\pi}{2}-\left(\theta+\frac{2(k-1) \pi}{3}\right)\right) i_{k}, \quad k=1,2,3 .
$$

Thus, the electromagnetic torque of the induction motor with a wound rotor is equal to

$$
M_{e m}=M_{1}+M_{2}+M_{3} .
$$

The dynamics of the rotating induction motor is described by the equations of electric chains (voltage equations) and the equation of moments of forces, acting on the motor rotor (equation of moments).

Using the second Kirchgoff's law and following the positive direction of the by-pass of the circuit in the clockwise order, one arrives at the following differential equations

$$
\begin{aligned}
& L\left(\dot{i}_{1}-\dot{i}_{2}\right)+R\left(i_{1}-i_{2}\right)=\varepsilon_{1}-\varepsilon_{2}, \\
& L\left(\dot{i}_{2}-\dot{i}_{3}\right)+R\left(i_{2}-i_{3}\right)=\varepsilon_{2}-\varepsilon_{3},
\end{aligned}
$$

where $R, L$ are active and inductive resistance of each coil; $\varepsilon_{k}$ is EMF, induced in $k$-th coil by rotating magnetic field.

The motion of wound rotor of induction motor about shaft in the chosen coordinate system is described by the equation of torques:

$$
J \ddot{\theta}=M_{e m}-M_{f},
$$

where $\theta$ is mechanical angle of rotor rotation; $J$ is inertia moment of the rotor relative to shaft; $M_{e m}$ is electromagnetic torque; $M_{l}$ is load torque.

Thus, the system of differential equations

$$
\begin{aligned}
& J \ddot{\theta}=n B S \sum_{k=1}^{n} i_{k} \cos \left(\frac{\pi}{2}-\theta-\frac{2(k-1) \pi}{3}\right)-M_{f}, \\
& L \dot{i_{1}}+R i_{1}=-n B S \dot{\theta} \cos \left(\frac{\pi}{2}-\theta\right), \\
& L \dot{i_{2}}+R i_{2}=-n B S \dot{\theta} \cos \left(\frac{\pi}{2}-\theta-\frac{2 \pi}{3}\right), \\
& L \dot{i_{3}}+R i_{3}=-n B S \dot{\theta} \cos \left(\frac{\pi}{2}-\theta-\frac{4 \pi}{3}\right)
\end{aligned}
$$


describes the dynamics of induction motor with a wound rotor.

Note that non-singular change of variables (4), makes it possible to reduce system (49) to the model used in (5) ${ }^{1}$.

$1 \quad$ Some other types of induction motors may also be reduced to this model under certain additional assumptions (Leonhard, 2001; Khalil and Grizzle, 2002) 


\section{APPENDIX 5 PROOF OF THE THEOREM ON LOCAL STABILITY}

\section{Proof}

In case when

$$
0<\gamma<\gamma_{\max }=\frac{a}{2}
$$

system (7) has one equilibrium state:

$$
u_{0}=s_{0}, \quad x_{0}=-\frac{\gamma}{a c} s_{0}, \quad y_{0}=-\frac{\gamma}{a}, \quad \theta_{r e l 0}=\frac{\gamma}{k_{\theta}} .
$$

Here $s_{0}$ is the smallest root of the equation

$$
\frac{a c s}{c^{2}+s^{2}}=\gamma \text {. }
$$

The characteristic polynomial of the first approximation matrix of (7) in stationary point (50) is as follows:

$$
p_{1}(\lambda)=a_{0} \lambda^{5}+a_{1} \lambda^{4}+a_{2} \lambda^{3}+a_{3} \lambda^{2}+a_{4} \lambda+a_{5},
$$

where

$$
\begin{aligned}
& a_{0}=1, \\
& a_{1}=2 c, \\
& a_{2}=\frac{1}{2 J_{u}}\left(a+2 k_{\theta}+D\right)+\frac{1}{2 J_{l} \gamma^{2}}\left(2 \gamma^{2} k_{\theta}+J_{l} a^{2} c^{2}-J_{l} a c^{2} D\right), \\
& a_{3}=\frac{c}{J_{u} J_{l}}\left(\left(2 k_{\theta}+D\right) J_{l}+2 J_{u} k_{\theta}\right), \\
& a_{4}=\frac{k_{\theta}}{2 J_{u} J_{l} \gamma^{2}}\left(\gamma^{2} a+\gamma^{2} D+J_{l} a^{2} c^{2}+J_{u} a^{2} c^{2}-J_{l} a c^{2} D-J_{u} a c^{2} D\right), \\
& a_{5}=\frac{c D k_{\theta}}{J_{u} J_{l}} .
\end{aligned}
$$

Here $D=\sqrt{a^{2}-4 \gamma^{2}}$. For defining stability, one uses Routh-Hurwitz stability criterion (Hurwitz, 1964; Routh, 1877) for a polynomial of the 5th order:

$$
\begin{gathered}
a_{i}>0, \quad i=0 . .5, \\
a_{1} a_{2}-a_{0} a_{3}>0, \\
\left(a_{1} a_{2}-a_{0} a_{3}\right)\left(a_{3} a_{4}-a_{2} a_{5}\right)-\left(a_{1} a_{4}-a_{0} a_{5}\right)^{2}>0 .
\end{gathered}
$$


Thus, the conditions (52) and (53) for the local stability of equilibrium state (50) are as follows ((51) holds automatically)

$$
\begin{aligned}
& \frac{a c}{J_{u}}+\frac{a c^{3}}{\gamma^{2}}(a-D)>0, \\
& \frac{1}{2 J_{u}^{3} J_{l} \gamma^{4}}\left(J_{l} \gamma^{2} a^{2} c^{4} k_{\theta}\left(D(a-D)+2 k_{\theta}(a-D)\right)+J_{u} J_{l} a^{2} c^{6} D k_{\theta}(D-a)^{2}+4 \gamma^{4} a^{2} c^{2} k_{\theta}^{2},\right. \\
& \left.+4 J_{u} \gamma^{2} a^{2} c^{4} k_{\theta}^{2}(a-D)\right)>0 .
\end{aligned}
$$

Therefore, equilibrium state (50) is asymptotically stable. 


\section{APPENDIX 6 COMPUTER ASSISTED MODELLING OF TWO-MASS MATHEMATICAL MODEL OF THE DRILLING SYSTEM(MATLAB IMPLEMENTATION)}

This code is based on templates of the files which can be found in (Piiroinen, 2007).

Function "run_drill.m" builds a 3D plot of solutions of the system describing two-mass mathematical model of the drilling system.

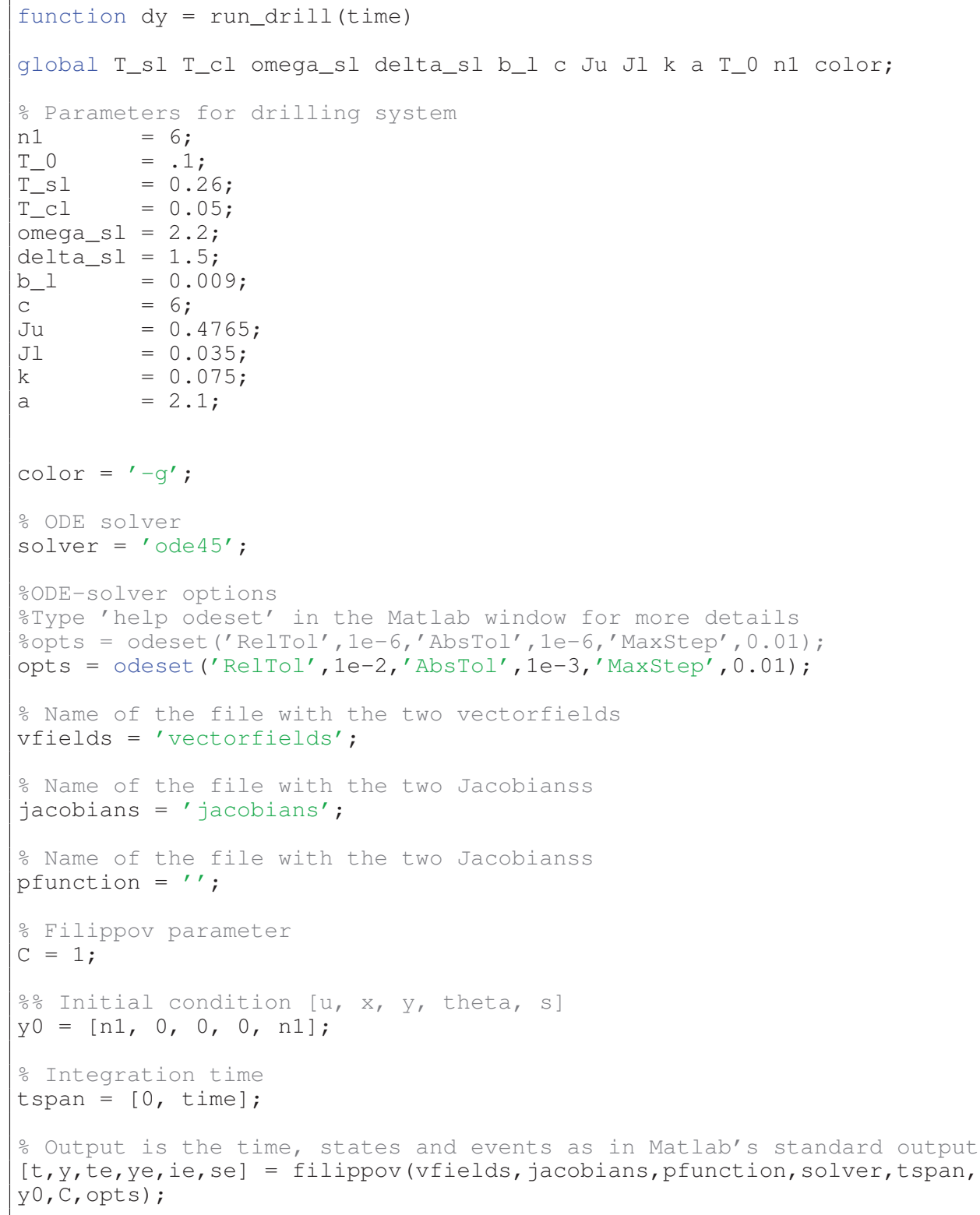


Function 'run_drill.m" calls the file "filippov.m", which takes care of the event handling and also calls the MATLAB built-in ODE solver and event detector

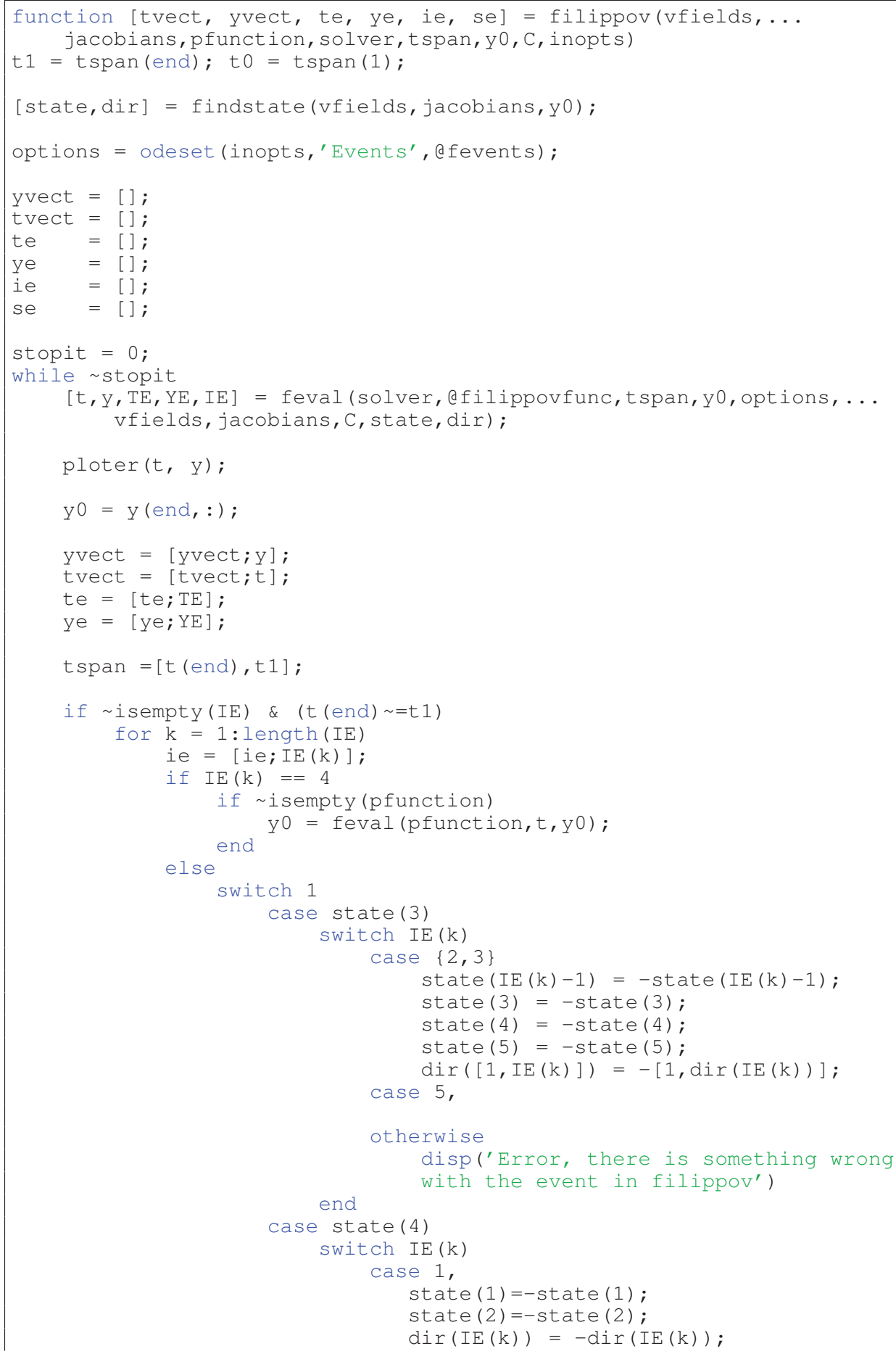




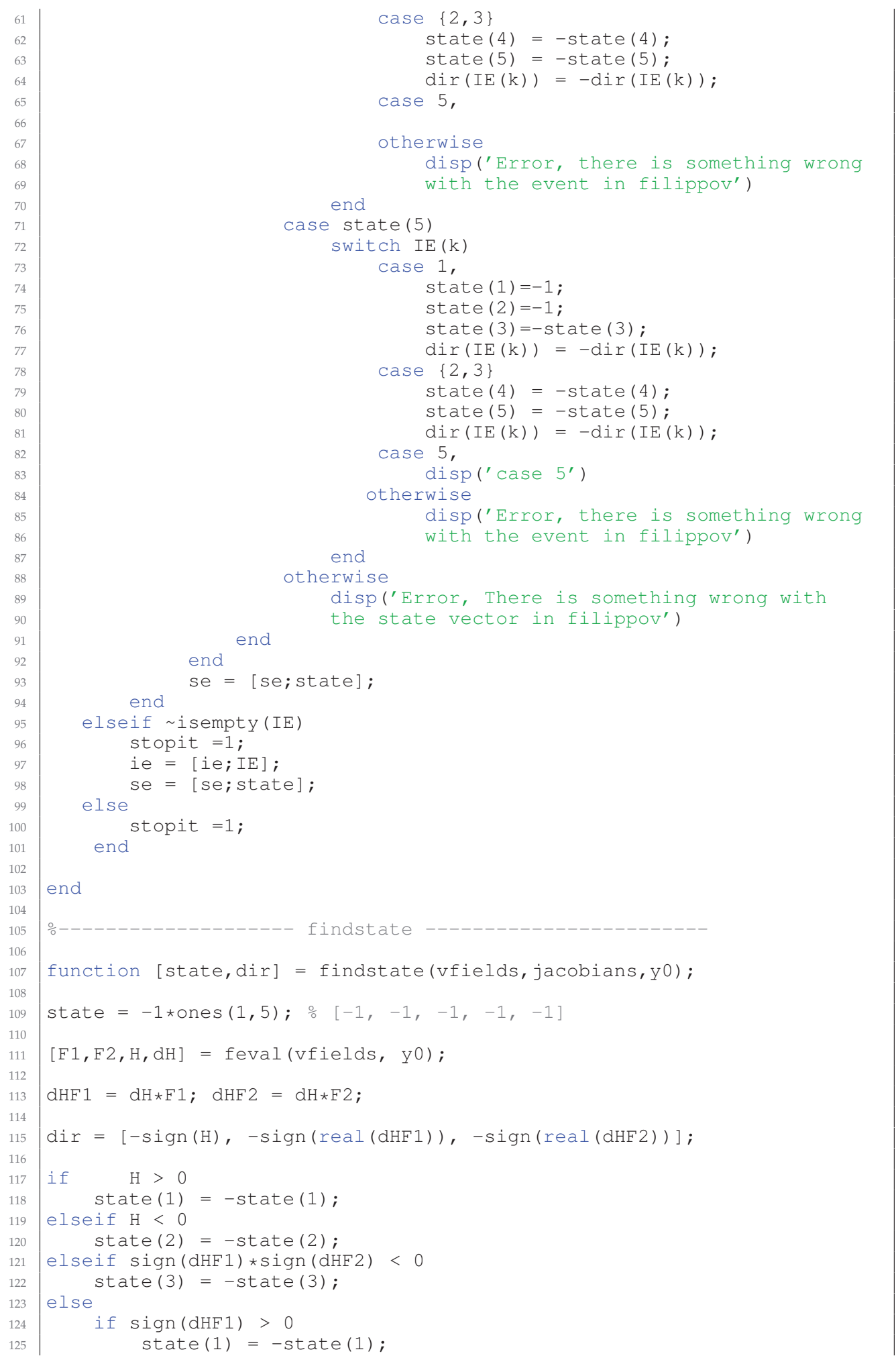


66

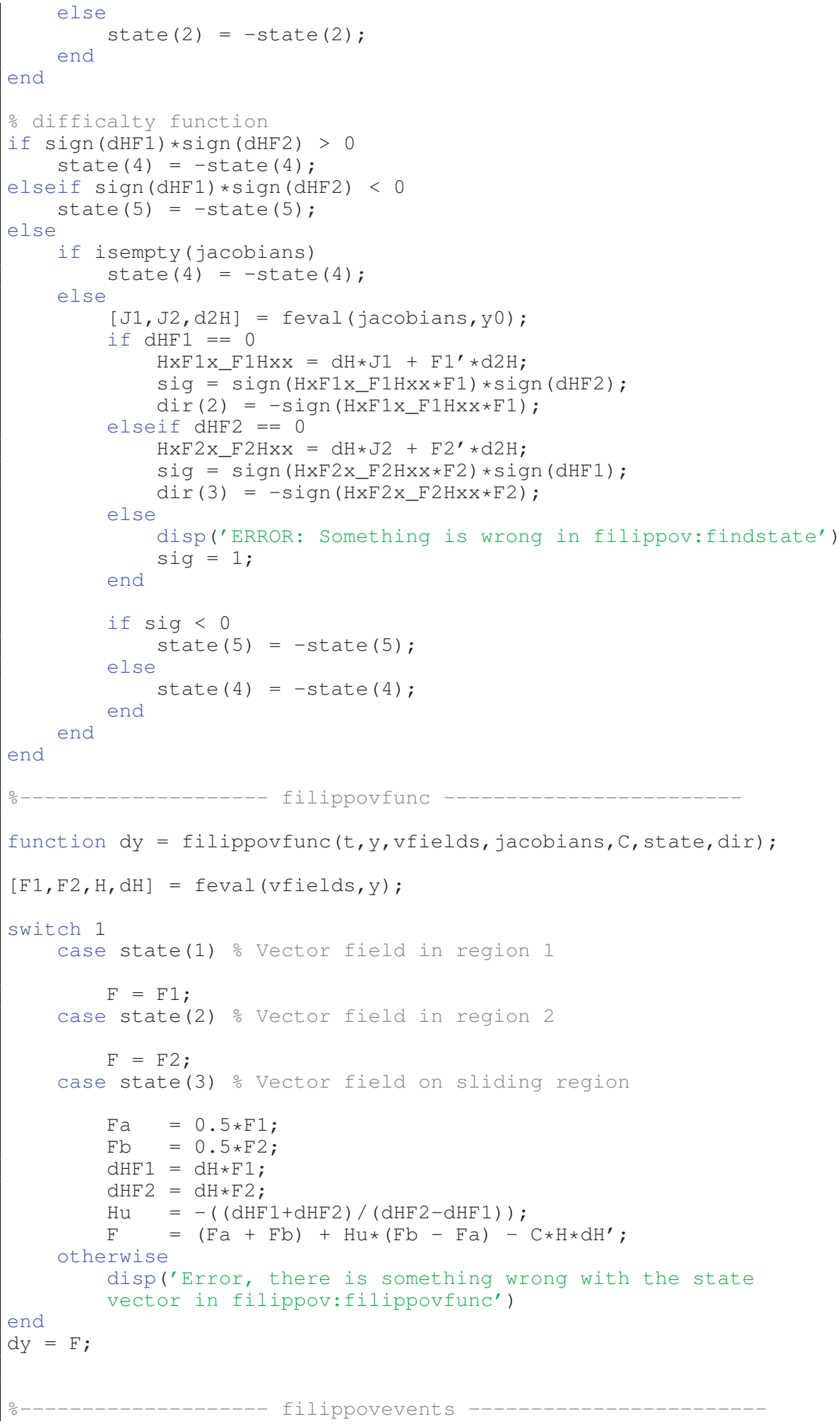


function [value, isterminal, direction]

= fevents (t,y, vfields, jacobians, C, state, dir);

$[\mathrm{F} 1, \mathrm{~F} 2, \mathrm{H}, \mathrm{dH}]=$ feval (vfields,y);

$\mathrm{dHF} 1=\mathrm{dH} * \mathrm{~F} 1$;

$\mathrm{dHF} 2=\mathrm{dH} * \mathrm{~F} 2$;

value $=[\mathrm{H}, \mathrm{dHF} 1, \mathrm{dHF} 2]$;

direction $=$ dir;

switch 1

case $\{$ state (1), state (2) \}

direction(1) = -state(1);

value $=[$ value, 1$]$;

direction $=[$ direction, 0$]$;

case state(3)

value $(1)=1$;

if isempty (jacobians)

value $\quad=$ [value, 1$]$ i

direction $=[$ direction, 0$]$;

else

$[\mathrm{J} 1, \mathrm{~J} 2, \mathrm{~d} 2 \mathrm{H}]=$ feval (jacobians, $\mathrm{y})$;

dHF1_P_dHF2 $=\mathrm{dHF} 1+\mathrm{dHF} 2$

dHF2_dHF1 = dHF2 - dHF1;

$\mathrm{Hu}=-\left(\left(\mathrm{dHF} 1 \_\mathrm{p} \_\mathrm{dHF} 2\right) /\left(\mathrm{dHF} 2 \_\mathrm{dHF} 1\right)\right) ;$

$\mathrm{F} 2$ - F1 $=\mathrm{F} 2-\mathrm{F} 1$;

$\mathrm{F} 2 \_\mathrm{F} 1{ }_{2} 2=0.5 * \mathrm{~F} 2 \_\mathrm{F} 1$

F1_P_F2 = F1+F2;

F1_P_F2_2 $=0.5 *$ F1_P_F2;

J2_J1 = J2-J1;

J2_J1_2 = 0.5*J2_J1;

J1_P_J2 = J1+J2;

J1_P_J2_2 $=0.5 * J 1 \_$P_J2;

$\mathrm{dHu}=-\left(\left(\left(\mathrm{F} 1 \_\mathrm{P} \_\mathrm{F} 2^{\prime}\right) * \mathrm{~d} 2 \mathrm{H}+\mathrm{dH} *\left(\mathrm{~J} 1 \_\mathrm{P} \_\mathrm{J} 2\right)\right) *\left(\mathrm{dHF} 2 \_\mathrm{dHF} 1\right)-\ldots\right.$ $\left.\left(\left(\mathrm{F} 2 \_\mathrm{F} 1^{\prime}\right) * \mathrm{~d} 2 \mathrm{H}+\mathrm{dH} *\left(\mathrm{~J} 2 \_\mathrm{J} 1\right)\right) *\left(\mathrm{dHF} 1 \_\mathrm{P} \_\mathrm{dHF} 2\right)\right) / \ldots$ $\left(\mathrm{dHF} 2 \mathrm{dHF} 1^{\wedge} 2\right)$;

$\mathrm{F}=\left(\mathrm{F} 1 \_\mathrm{P} \_\mathrm{F} 2 \_2\right)+\left(\mathrm{F} 2 \_\mathrm{F} 1 \_2\right) * \mathrm{Hu}-\mathrm{C} * \mathrm{H} * \mathrm{dH}^{\prime} ;$

$\mathrm{dHuF}=\mathrm{dHu} * \mathrm{~F}$;

value $=$ [value, $\mathrm{dHuF}]$;

end

direction $=[$ direction, 0$]$;

otherwise

end

disp('ERROR: Wrong event in filippov: fevents')

value = real (value)

isterminal $=[1,1,1,0]$;

function [] $=\operatorname{ploter}(t, z)$;

응 Parameters

global ...

color n1;

$\div$ Variables

$\begin{array}{ll}\mathrm{u} & =\mathrm{z}(:, 1) ; \\ \mathrm{x} & =\mathrm{z}(:, 2) ;\end{array}$ 


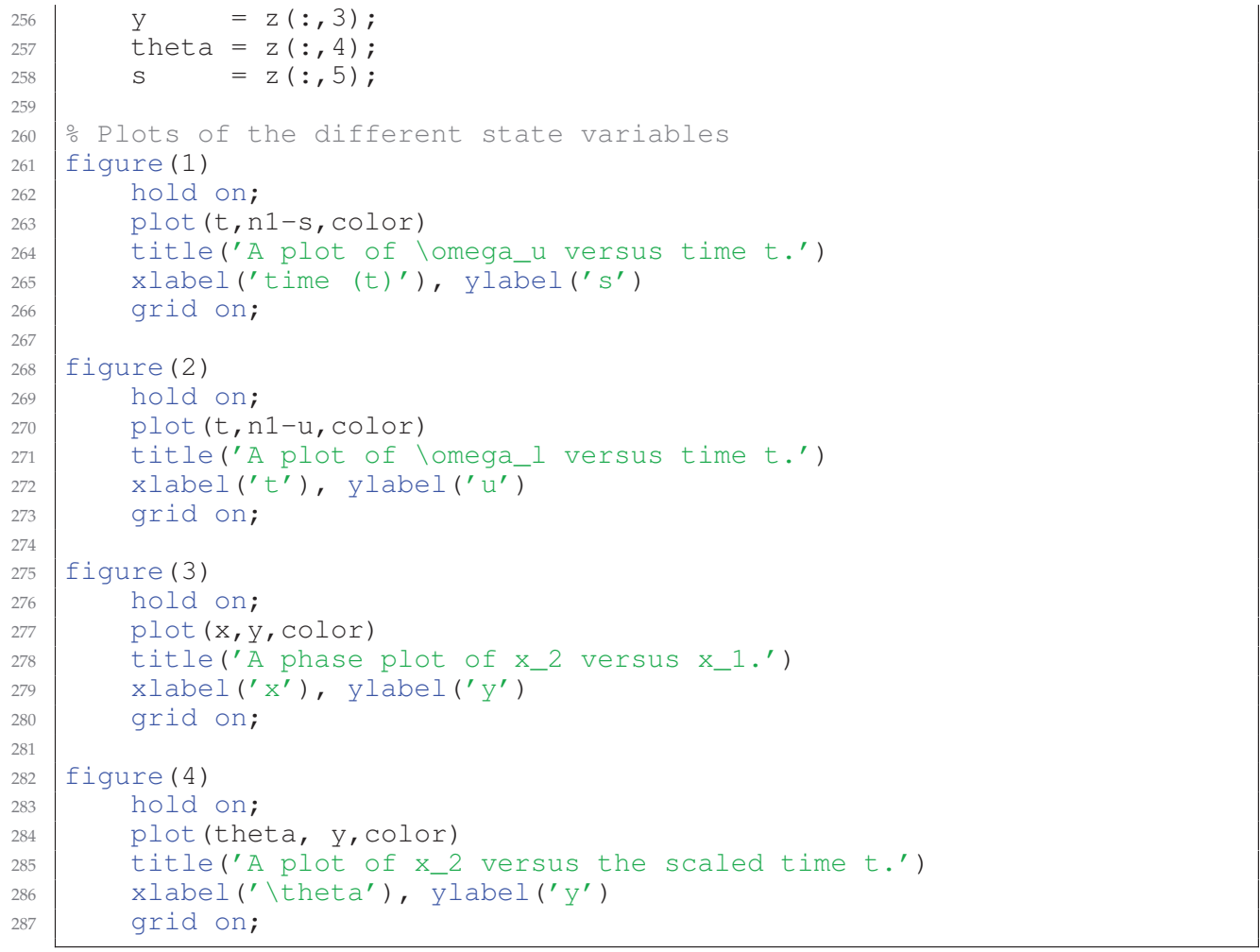

